\title{
Air-sea fluxes in a climate model using hourly coupling between the atmospheric and the oceanic components
}

\author{
Fangxing $\operatorname{Tian}^{1,2}{ }^{\mathbb{D}} \cdot$ Jin-Song von $\operatorname{Storch}^{1} \cdot$ Eileen Hertwig $^{1}$
}

Received: 5 January 2016 / Accepted: 3 June 2016 / Published online: 27 June 2016

(C) The Author(s) 2016. This article is published with open access at Springerlink.com

\begin{abstract}
We analyse the changes in the air-sea fluxes of momentum, heat and fresh water flux caused by increasing the ocean-atmosphere coupling frequency from once per day to once per hour in the Max Planck Institute Earth System Model. We diagnose the relative influences of daily averaging and high-frequency feedbacks on the basic statistics of the air-sea fluxes at grid point level and quantify feedback modes responsible for large scale changes in fluxes over the Southern Ocean and the Equatorial Pacific. Coupling once per hour instead of once per day reduces the mean of the momentum-flux magnitude by up to $7 \%$ in the tropics and increases it by up to $10 \%$ in the Southern Ocean. These changes result solely from feedbacks between atmosphere and ocean occurring on time scales shorter than 1 day. The variance and extremes of all the fluxes are increased in most parts of the oceans. Exceptions are found for the momentum and fresh water fluxes in the tropics. The increases result mainly from the daily averaging, while the decreases in the tropics are caused by the high-frequency feedbacks. The variance increases are substantial, reaching up to $50 \%$ for the momentum flux, $100 \%$ for the fresh water flux, and a factor of 15 for the net heat flux. These diurnal and intra-diurnal variations account for up to 50-90\% of the total variances and exhibit distinct seasonality. The high-frequency coupling can influence the large-scale feedback modes that lead to large-scale changes in the magnitude of wind stress over the Southern Ocean and Equatorial Pacific. In the Southern Ocean,
\end{abstract}

Fangxing Tian

fangxing.tian@mpimet.mpg.de

1 Max Planck Institute for Meteorology, Hamburg, Germany

2 International Max Planck Research School on Earth System Modelling, 20146 Hamburg, Germany the dependence of the SST-wind-stress feedback on the mean state of SST, which is colder in the experiment with hourly coupling than in the experiment with daily coupling, leads to an increase of westerlies. In the Equatorial Pacific, Bjerknes feedback in the hourly coupled experiment reveals a diurnal cycle during the El Niño events, with the feedback being stronger in the nighttime than in the daytime and no clear diurnal cycle during the La Niña events. This asymmetry might lead to the decrease of wind stress in the Equatorial Pacific in the hourly coupled experiment.

Keywords Air-sea flux · High-frequency coupling . Intra-daily air-sea feedback · ENSO asymmetry $\cdot$ Bjerknes feedback $\cdot$ Sea surface wind stress

\section{Introduction}

The atmosphere and ocean are coupled by continuous exchanges of momentum, heat and fresh water. So far the diurnal cycle and the intra-diurnal fluctuations of these exchanges, which result mainly from atmospheric turbulence, are generally not resolved by the state-of-the-art coupled climate models that usually use a coupling frequency of once per day. For example, more than half of the CMIP5 models that contributed to the fifth assessment report (AR5) of IPCC, including the Max Planck Institute Earth System Model (MPI-ESM), exchange fluxes between atmosphere and ocean once per day, so air-sea exchanges on time scales shorter than one day are excluded. This paper focuses on features resolved by a standard CMIP5 model, the MPI-ESM, to study the effects induced by increasing the coupling frequency to once per hour.

Increasing the coupling frequency can lead to significant changes in many aspects of the coupled system, such as 
those on the simulation of sea surface temperature (SST), Madden-Julian Oscillation (MJO), and El Niño- Southern Oscillation (ENSO). By increasing the coupling frequency from once per day to once per 1- or 3-h, the mean equatorial SST is warmed by as much as $1^{\circ} \mathrm{C}$, which is in better agreement with observations (Danabasoglu et al. 2006). The meridional SST gradient in the North Atlantic is decreased (Guemas et al. 2013). The cold bias in the eastern tropical Pacific is reduced (Misra et al. 2008). For the variability on intra-seasonal and inter annual scales, including the diurnal cycle in the SST strongly influences the onset and intensity of MJO convection (Seo et al. 2014) and leads to a distinct improvement of the simulated intra-seasonal oscillation signal (Ham et al. 2014). The simulated MJO is stronger and more coherent (Bernie et al. 2008). The simulation of ENSO is also improved (Danabasoglu et al. 2006; Terray et al. 2012). Most of the changes considered in previous studies are the consequences of changed air-sea fluxes due to an enhanced coupling frequency. However, few studies have systematically addressed the direct impact of the coupling frequency on the air-sea fluxes. This paper fill this gap and addresses the influence of high-frequency coupling on both the basic statistics of air-sea fluxes at grid point level and the feedbacks leading to large scale air-sea flux changes.

The basic statistics of the air-sea fluxes are known to be important to the simulated climate. For example, Walin (1982) found that the mean heat flux at the sea surface directly determines the surface poleward branch of the meridional circulation. Tziperman (1986) revealed that time-mean density and velocity fields are forced by the mean wind stress and heat fluxes at the upper surface of the ocean. Not only the long-term mean but also the fluctuation and associated variance of the air-sea fluxes play an important role in determining the general circulation of the climate system. Kuhlbrodt and Monahan (2003) found that the variability of surface fluxes leads to frequent deep convection and more deep water formation in the Labrador Sea. It was also found that the fluctuating fluxes change the intensity and the depth of vertical mixing, SST, Hadley circulation, and sea surface net upward water flux (Beena and von Storch 2009; Williams 2012). The extremes resulting from atmospheric turbulence or the diurnal cycle can also influence the simulated climate. Bernie et al. (2007) found that extremes related to the diurnal cycle of solar insolation affect the mixed layer depth and increase the sea surface temperature. These previous works, although not directly addressing changes in fluxes due to enhanced coupling frequency, clearly demonstrate the importance of the basic statistics of the air-sea fluxes for the climate system. Here we first quantify the basic statistics of air-sea fluxes at each grid point. We then study modes of air-sea feedbacks that can lead to large-scale changes in the fluxes.

The structure of this paper is as follows: Sect. 2 gives a brief description of the model and experiments used in this work. Section 3 quantifies the changes of mean, variance and extreme values of air-sea fluxes in the high-frequency coupling experiment, and discusses the causes of the changes, respectively. Section 4 identifies large-scale feedbacks between the fluxes and SST. Conclusions are given in Sect. 5 .

\section{The model experiments}

The experiments are performed with the Max Planck Institute for Meteorology Earth System Model (MPI-ESM), which consists of the general circulation models for the atmosphere [ECHAM6, Stevens et al. (2013)] and for the ocean [MPIOM, Jungclaus et al. (2006), Jungclaus et al. (2010)]. Here we use the model version MPI-ESM-LR, meaning that ECHAM6 is run at T63 horizontal resolution (approximately $1.875^{\circ}$ on a Gaussian grid) with 47 vertical levels. The realism of the simulated climate is discussed in (Hertwig et al. 2015; Giorgetta et al. 2013; Stevens et al. 2013; Jungclaus et al. 2013).

MPIOM uses a bipolar grid with horizontal resolution of about $1.5^{\circ}$ and 40 vertical levels, the surface model layer is $12 \mathrm{~m}, 8$ layers are within the upper $90 \mathrm{~m}$ and 20 are within the upper $600 \mathrm{~m}$. The same model has been used for CMIP5 simulations (Jungclaus et al. 2010). ECHAM6 and MPIOM are coupled without flux adjustments using the OASIS3 coupler (Valcke et al. 2003), in which the air-sea fluxes of momentum, heat and fresh water are averaged over each coupling time step. After averaging, the fluxes are exchanged between the atmospheric and oceanic components. Interactions between the atmosphere and the ocean can occur only on time scales longer than the coupling time step.

We perform two experiments with MPI-ESM-LR that are identical except for the coupling frequency. The first one has a coupling frequency of once per day and is called Daily Coupling $(D C)$ experiment. The other experiment has a coupling frequency of once per hour and is called Hourly Coupling $(H C)$ experiment.

The experiment $\mathrm{HC}$ and DC are run for multi centuries under pre-industrial (1850) boundary conditions so that the atmosphere and the upper ocean have reached a quasi-equilibrium. We use the daily mean of the last 100 years of the two experiments and 50 years of the hourly mean data of experiment $H C$ to study the changes induced by different coupling frequencies. 


\section{Disentangling two different effects of coupling frequency at grid point level}

\subsection{The methods}

We concentrate on three fluxes that are exchanged between ECHAM6 and MPIOM: the momentum flux, the net heat flux and the fresh water flux. For the momentum flux, we focus on the magnitude of wind stress $|\tau|$. The net heat flux is the sum of short- and long-wave radiation and latent and sensible heat flux. The fresh water flux is the sum of the total precipitation, evaporation and the river run-off. Downward net heat flux and fresh water flux have positive values.

The total effect induced by increasing the coupling frequency from once per day to once per hour is quantified by the ratio of a statistic $S$ derived from hourly fluxes in experiment $H C$ to the same statistic derived from daily fluxes in experiment $D C, S_{h, H C} / S_{d, D C}$. Here the subscript $d$ and $h$ indicates that $S$ is derived form daily and hourly values respectively, and $H C$ and $D C$ denote experiments $H C$ and $D C$, respectively. The statistical quantities $S$ considered are the mean $\mu$, the variance $\sigma^{2}$, and the extreme values in form of the 10th and 90th percentile $q_{10}$ and $q_{90}$.

The effect described by $S_{h, H C} / S_{d, D C}$ can be decomposed into two factors. First, to quantify the effect induced by the daily averaging only, we consider the ratio of a statistic obtained from hourly fluxes in experiment $H C, S_{h, H C}$, to the same statistic derived from a daily averaging of the fluxes in the same experiment, $S_{d, H C}, S_{h, H C} / S_{d, H C}$. By considering hourly and daily fluxes within experiment $H C$, any possible changes arising from differences between experiment $H C$ and $D C$ (i.e. high-frequency feedbacks) are excluded from the analysis, allowing us to isolate the effect of averaging.

Secondly, changes in statistics can also arise from interactions between the atmosphere and the ocean on diurnal and intra-diurnal time scales. These interactions are accounted for in experiment $H C$, but are completely missing in experiment $D C$. For instance, consider an hourly wind stress time series containing a few strong wind bursts occurring within a time period of one day. These wind stresses can produce a stronger decrease in SSTs than the daily averaged wind stresses. Due to differences in SSTs, the hourly heat fluxes in experiment $H C$ can behave differently from those in experiment $D C$. Hereafter, such interactions are referred to as high-frequency feedbacks. To quantify these feedbacks, we consider the ratio of the statistic $S$ derived from daily averaged fluxes in experiment $H C$ to the same statistic derived from the daily fluxes in experiment $D C, S_{d, H C} / S_{d, D C}$. Both daily fluxes have been subjected to the same averaging procedure, so that the effect of averaging is excluded. However, the daily fluxes from experiment $H C$ contain, in an averaged sense, the effect of highfrequency feedbacks, which is absent in experiment $D C$.
The comparison allows us to identify the daily averaged effect of high-frequency feedbacks. The total effect can be expressed as the product of the other two effects:

$\underbrace{S_{h, H C} / S_{d, D C}}_{\text {total }}=\underbrace{\left(S_{h, H C} / S_{d, H C}\right)}_{\text {averaging }} \times \underbrace{\left(S_{d, H C} / S_{d, D C}\right)}_{\text {feedback }}$

In case $S$ represents the mean, $\mu_{h, H C}$ equals $\mu_{d, H C}$. The total effect results from high-frequency feedbacks only. In case $S$ represents variance $\sigma^{2}$ or percentiles $q, S_{h, H C}$ is generally different from $S_{d, H C}$. Both the effects of averaging and that of high-frequency feedbacks may be present.

To quantify the strength and the seasonality of intradiurnal and diurnal fluctuations, we decompose the flux $F$ as $F=\bar{F}+F^{\prime}$, where $\bar{F}$ is the daily mean and $F^{\prime}$ is the hourly anomaly. The total variance is decomposed into variances resulting from variations on intra-diurnal and diurnal scales $F^{\prime}$ and inter-diurnal time scales $\bar{F}$. Both variances can be obtained from experiment $\mathrm{HC}$, whereas only the variance of $\bar{F}$ can be obtained from experiment DC. Generally, if the diurnal cycle dominates turbulent motions, the time series of $F^{\prime}$ reveals a deterministic oscillation with the period of $24 \mathrm{~h}$; otherwise the time series of $F^{\prime}$ reveals irregular intra-diurnal variations. Both types of variances vary with seasons. This seasonal dependence is quantified by considering the variances of $F^{\prime}$ in different seasons.

\subsection{Regarding the mean}

The long-term mean of the air-sea fluxes simulated in experiment $D C$ are shown in Fig. 1a-c. When increasing the coupling frequency from once per day in experiment $D C$ to once per hour in experiment $H C$, the long-term mean of the momentum-flux magnitude is systematically changed (Fig. 1d). The momentum flux ratio between experiment HC and DC is larger than 1 in the Southern Ocean along the Antarctic Circumpolar Currents (ACC) and smaller than 1 over the tropical oceans, in particular over the western Equatorial Pacific, and along about $40^{\circ} \mathrm{S}$. A dipole pattern exists over the Southern Ocean: the momentum-flux is increased in the ACC by up to about $10 \%$ and is decreased in the subtropical regions near $35^{\circ} S-40^{\circ} S$ by about $5 \%$. In the Equatorial Pacific, the magnitude is decreased reaching about $7 \%$. The changes in the long-term mean of the net heat flux have small spatial scales and are mostly not significant (Fig. 1e). Some significant changes in fresh water fluxes occur in the Southern Ocean, with a tendency for having reduced fluxes near $40^{\circ} S-50^{\circ} S$ (Fig. 1f). Other large changes are patchy and not well organized, and may not be of relevance.

As averaging cannot affect the mean of the fluxes, the above identified changes of the mean values have to result from intra-diurnal air-sea interactions that occur when 
(a) Momentum flux

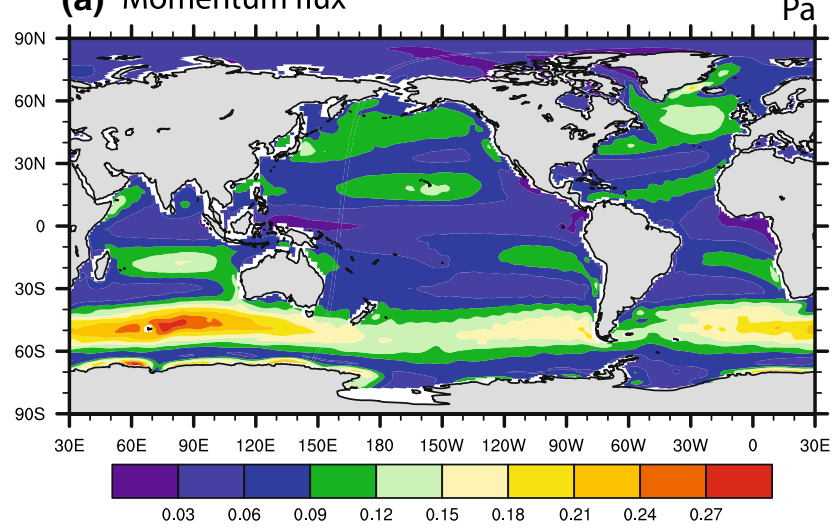

(b) Net heat flux

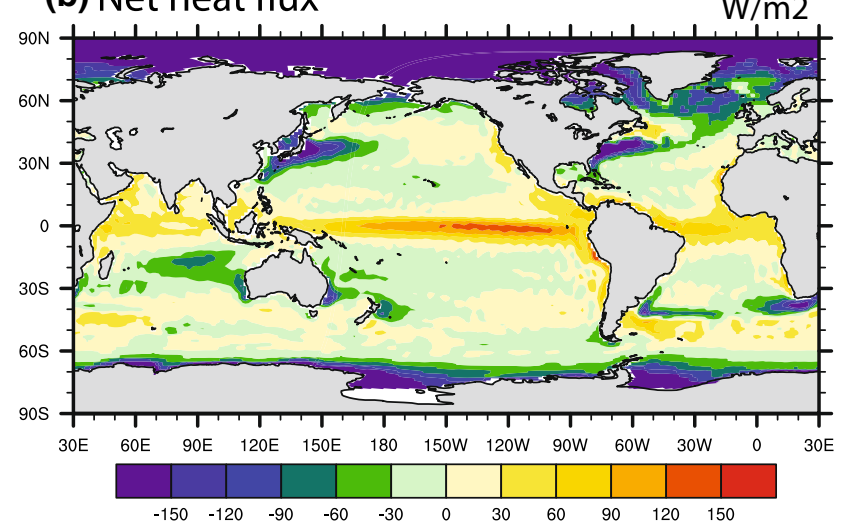

(c) Fresh water flux

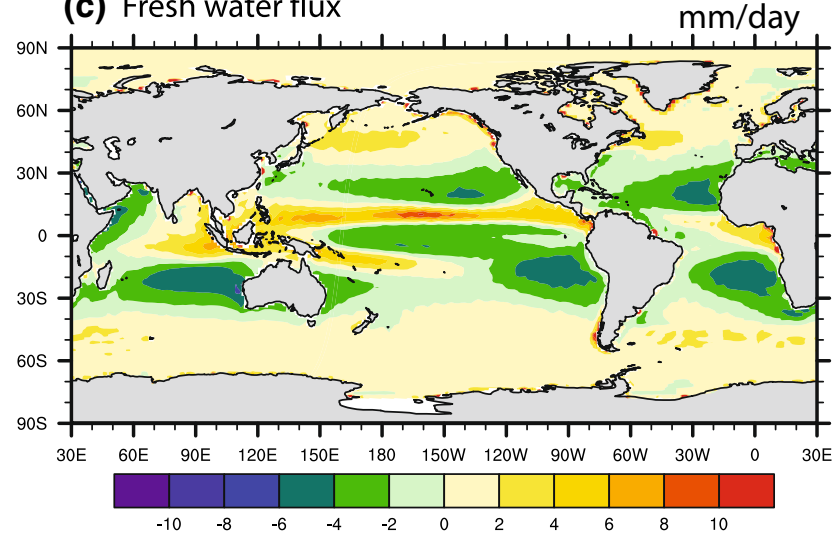

Fig. 1 Long-term mean air-sea fluxes simulated in daily coupled MPI-ESM (left column). a momentum flux (Pa), b net heat flux (W/ $\mathrm{m}^{2}$ ), $\mathbf{c}$ fresh water flux ( $\mathrm{mm} /$ day). Relative changes of time-mean air-

using hourly coupling. We will come back to this issue later in Sect. 4.

\subsection{Regarding the variance}

Following Sect. 3.1, the total effect on the variance induced by increasing the coupling frequency from once per day to once per hour is quantified by the ratios of the variances of hourly fluxes in experiment $H C$ to those of daily fluxes (d) Momentum flux

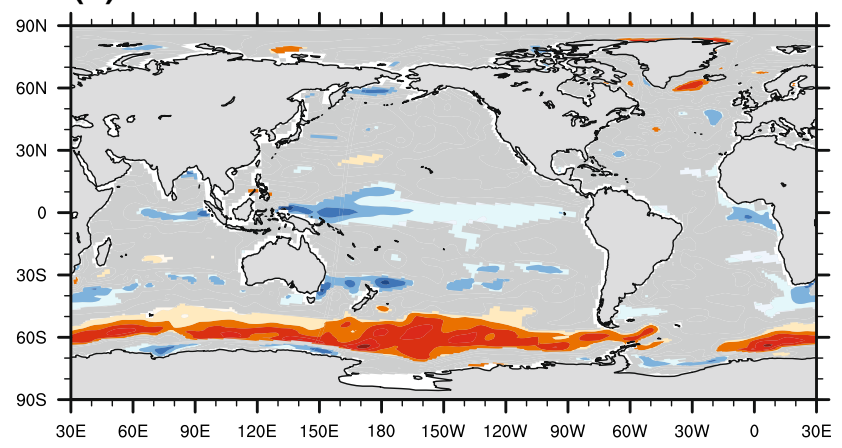

(e) Net heat flux

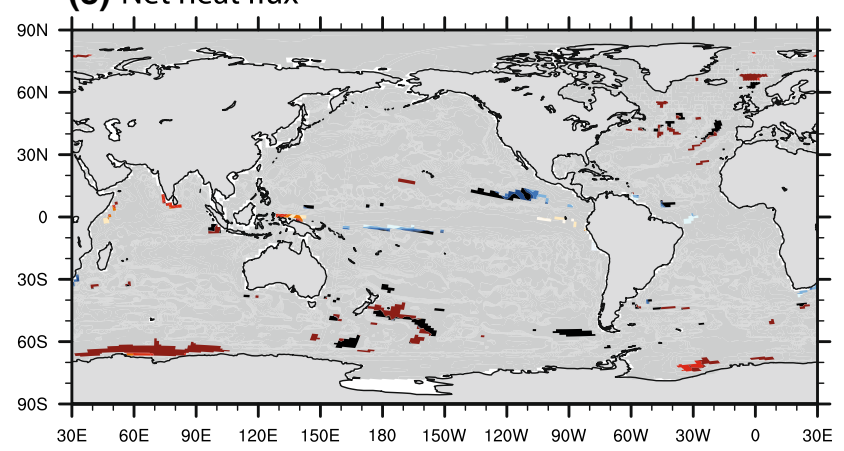

(f) Fresh water flux

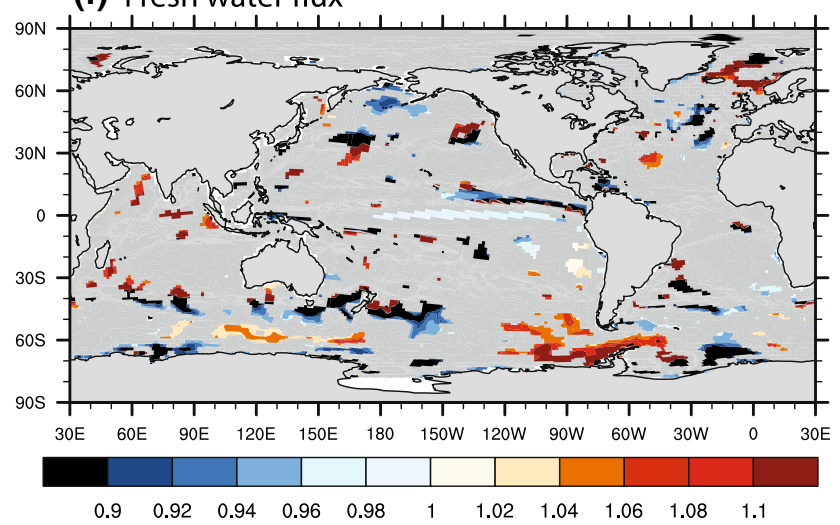

sea fluxes $\mu_{d, H C} / \mu_{d, D C}$ (right column): d magnitude of momentum flux, e net heat flux, $\mathbf{f}$ fresh water flux. The colours indicate no-zero differences at $5 \%$ significance level following a $t$ test

in experiment $D C$ (Fig. 2a-c). For the magnitude of the momentum flux (Fig. 2a), hourly coupling enhances the variances up to $50 \%$ poleward of $30^{\circ}$. The pattern is characterized by variance ratios that reach maximum values of about 1.5 around $40^{\circ} \mathrm{N}-50^{\circ} \mathrm{N}$ and $40^{\circ} \mathrm{S}-60^{\circ} \mathrm{S}$. Hourly coupling decreases the total momentum variance in some parts of the tropics, in particular in the western tropical Pacific. There, the variance from experiment $H C$ is about $20-30 \%$ smaller than those in experiment $D C$. 
(a) Momentum Flux

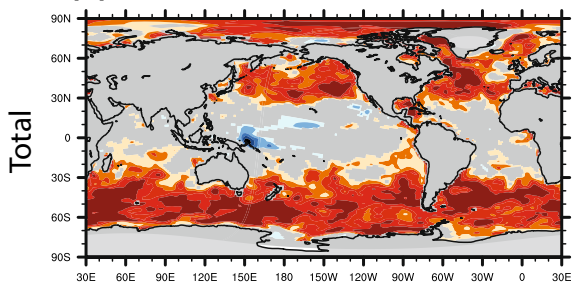

(d)

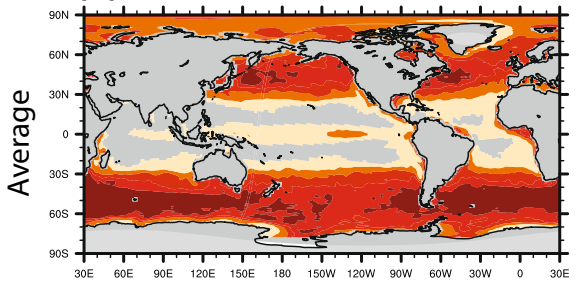

(g)

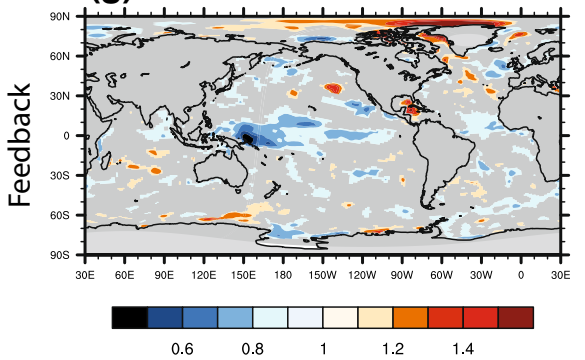

(b) Net Heat Flux

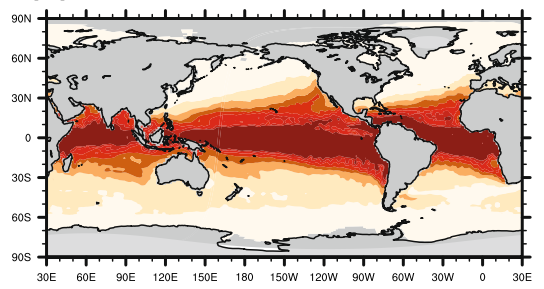

(e)

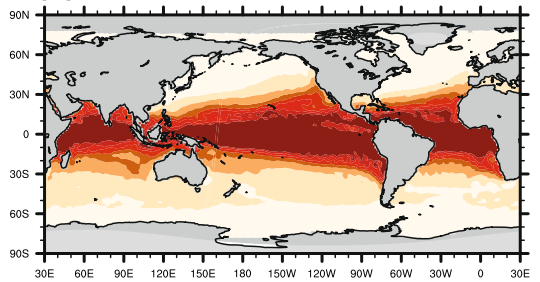

(h)
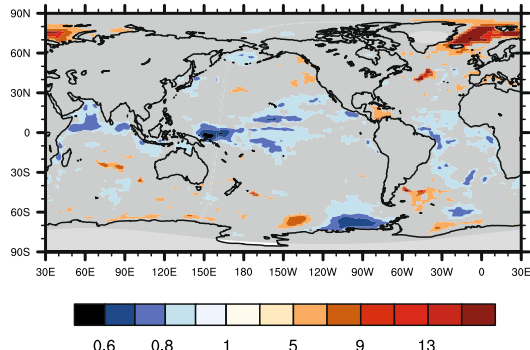

(c) Fresh Water Flux

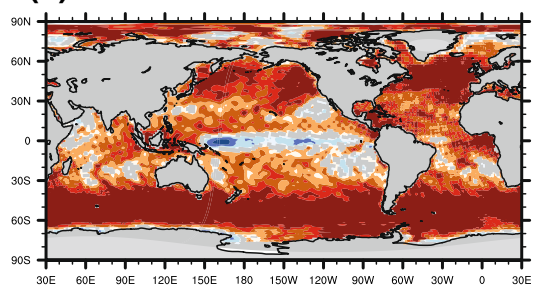

(f)

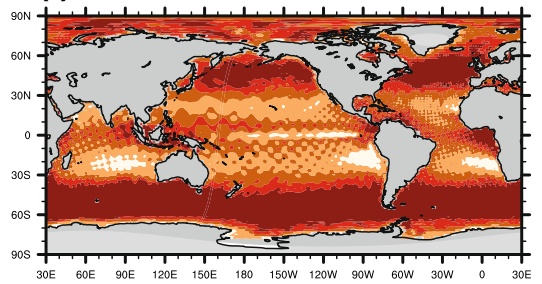

(i)
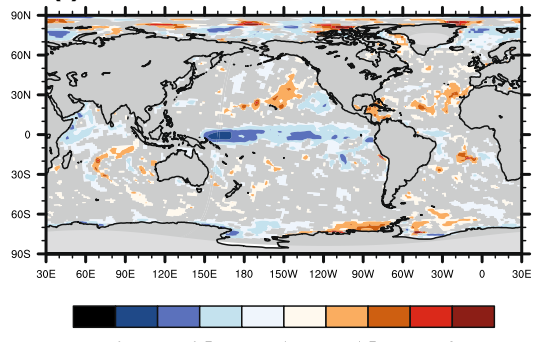

Fig. 2 Relative changes of the variance (expressed as variance ratios) with respect to the total changes in $\mathbf{a}-\mathbf{c}$, to changes caused by averaging in $\mathbf{d}-\mathbf{f}$, and to changes caused by high-frequency feedback in g-i, for the magnitude of momentum flux (left column), the net heat flux (middle column) and the fresh water flux (right column). Colours show non-unit ratios at $5 \%$ significant level following a $F$ test
For the net heat flux (Fig. 2b), hourly coupling drastically increases the variance. The variance ratios are larger than 1 almost everywhere. They increase equatorward and in the tropics the heat flux variance is more than 15 times greater in $H C$ than in $D C$.

For the fresh water flux (Fig. 2c), the variance ratio is larger than 2 poleward of $30^{\circ}$ with maximum values in the Southern Ocean and in the Northern Pacific and Atlantic. Over the Indian Ocean-Western Pacific warm pool and the tropical Atlantic the ratios are also larger than 1. In the Equatorial Pacific, the variances in experiment $H C$ are mostly smaller (up to 30-70 \%) than those in experiment $D C$.

The total effect induced by increasing the coupling frequency (top row in Fig. 2) can be decomposed into the effect due to daily averaging (middle row in Fig. 2) and the effect due to high-frequency feedbacks (bottom row in Fig. 2). Generally, the daily averaging used in experiment $D C$ affects all three fluxes by reducing the variances at almost all grid points (Fig. 2d-f), as indicated by substantially higher variances of hourly data than those of daily data in experiment $H C$. The spatial structures are comparable to those of the total change (Fig. 2a-c). Nevertheless, important differences exist in the tropics and subtropics. There the total effect on the variance is reduced by high-frequency feedbacks, which cause the variance of the surface fluxes to reduce in experiment $H C$ compared to $D C$ (Fig. 2g-i). This is particularly pronounced in the western tropical Pacific. Generally, the effect of daily averaging is clearly stronger than that of high-frequency feedbacks for momentum and fresh water fluxes in the mid- and highlatitudes and for heat flux all over the oceans. However, it is comparable to or even weaker than the effect of highfrequency feedbacks for momentum and fresh water fluxes over the tropical Pacific.

The daily averaging removes intra-diurnal fluctuations. To illustrate the significance of this reduction, the ratios of the variances of diurnal and intra-diurnal fluctuations to the total variances are examined (Fig. 3). The variances of diurnal and intra-diurnal fluctuations are defined in Sect. 3.1.

For the momentum flux, Fig. 3a shows that intra-diurnal fluctuations amount to $10 \%$ of the total variance in most of the regions, and reaching about $40 \%$ over the Southern Ocean. For the net heat flux (Fig. 3b), the intra-diurnal 
(a) Momentum flux

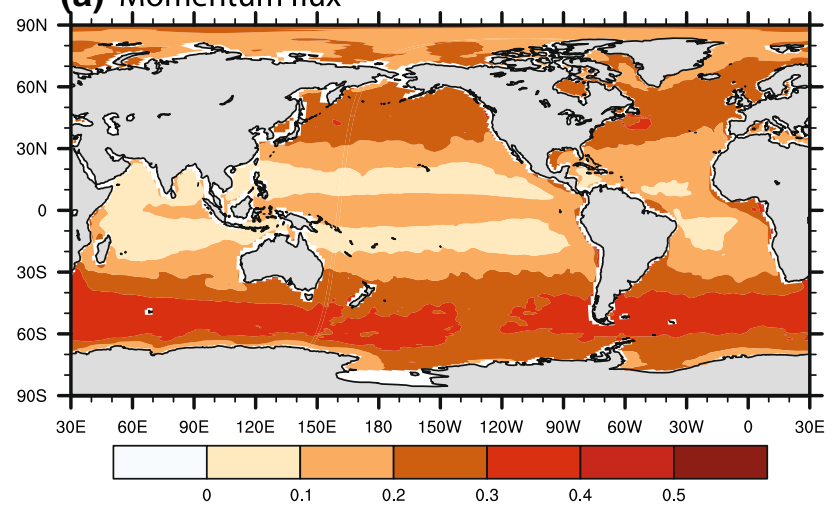

(b) Net heat flux

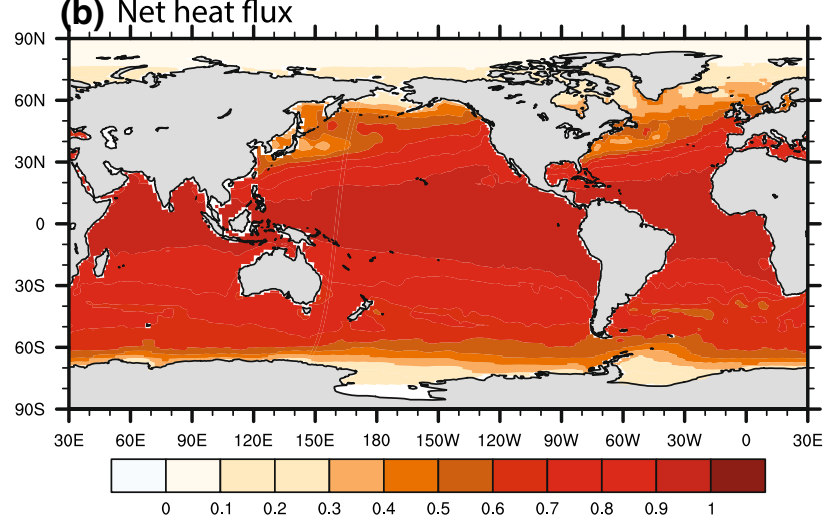

(c) Fresh water flux

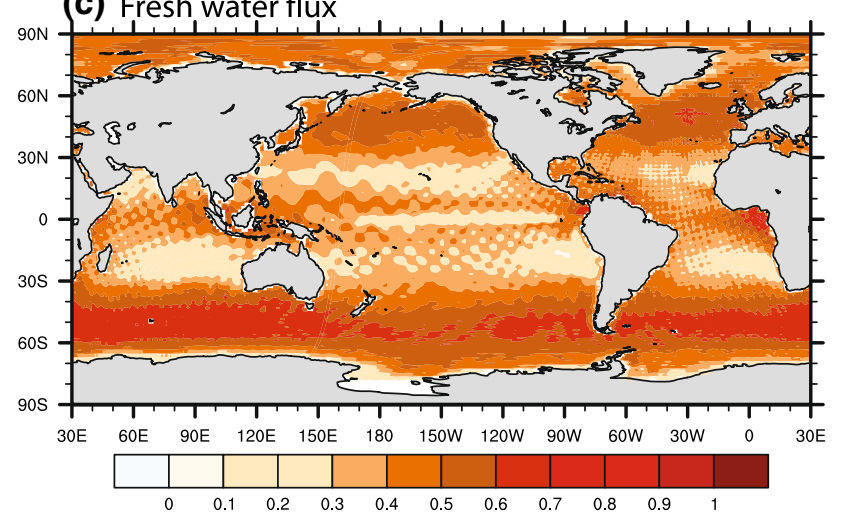

Fig. 3 Ratios of variance of diurnal and intra-diurnal fluctuation to the total variance of hourly fluxes of a momentum, $\mathbf{b}$ net heat, $\mathbf{c}$ fresh water. Hourly fluxes of experiment $\mathrm{HC}$ are used. The diurnal and intra-diurnal fluctuations are obtained by subtracting daily mean from the respective hourly fluxes

fluctuations become increasingly strong equatorward and reach $90 \%$ of the total variance in the tropics. At latitudes north of $60^{\circ} \mathrm{N}$ and south of $60^{\circ} \mathrm{S}$, the ratio is smaller than $60 \%$, but still accounts for more than half of the total variance. For the fresh water flux, the ratio has maxima in the Southern Ocean, which are larger than $60 \%$. In the area of the ITCZ and at the North Pacific and North Atlantic, the ratio is around $30 \%$ or more (Fig. 3c). (a) Momentum flux

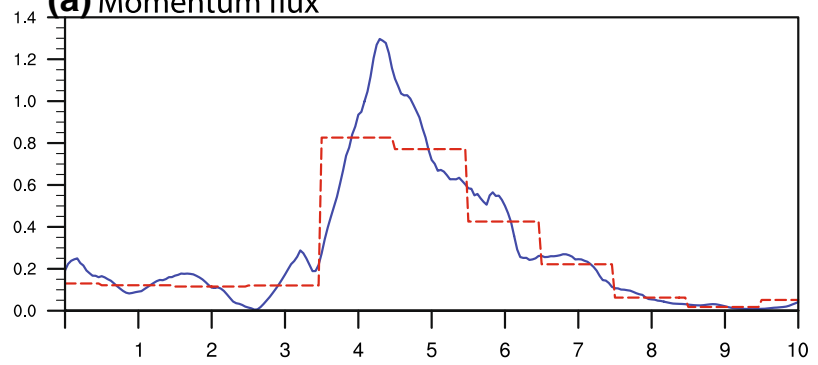

(b) Net heat flux

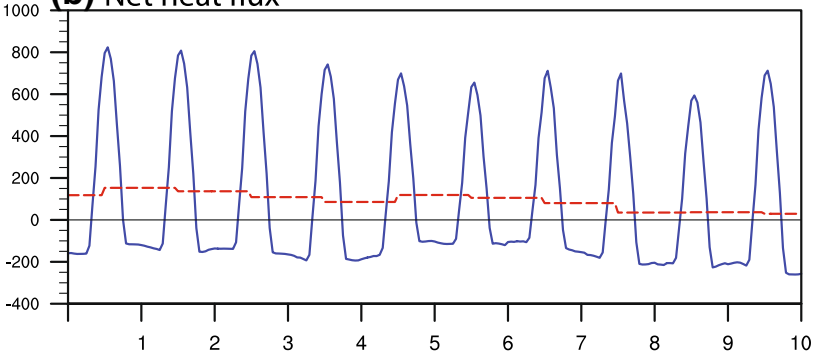

(c) Fresh water flux

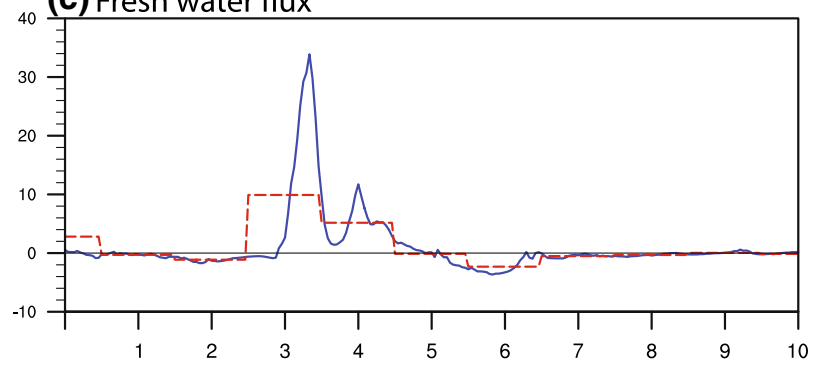

Fig. 4 Time series over 10 days for a the magnitude of momentum flux at grid point $60^{\circ} S 180^{\circ}(\mathrm{Pa}), \mathbf{b}$ net heat flux at grid point $0^{\circ} 180^{\circ}$ $\left(\mathrm{W} / \mathrm{m}^{2}\right)$, c fresh water flux at grid point $60^{\circ} \mathrm{S} 180^{\circ}\left(\mathrm{mm} / \mathrm{day}^{-1}\right)$ in experiment HC. Dashed lines are daily series, solid lines are hourly series

To understand how these changes come about, we consider a few time series of fluxes at grid points where large ratios are found (Fig. 4). Compared to the momentum and fresh water fluxes, the variance of the net heat flux is particularly large because of the strong diurnal cycle of solar radiation in the tropics (Fig. 4b). During nighttime, the hourly net heat flux is dominated by the sum of long wave radiation and sensible and latent heat flux, which are always negative (upward). During the daytime, the net heat flux is dominated by the downward solar radiation, which can reach very large (positive) values especially in the tropics at noon. The intradiurnal fluctuations of momentum and fresh water flux over the Southern Ocean are mainly due to high frequency turbulent motions that do not reveal regular diurnal cycles and are characterized by irregularly occurring events (Fig. 4a, c).

The strength of intra-diurnal fluctuations and the diurnal cycle, as described by the variance of $F^{\prime}$, varies with seasons. For the momentum flux (left column of Fig. 5), the fluctuations are most pronounced in the winter hemisphere 

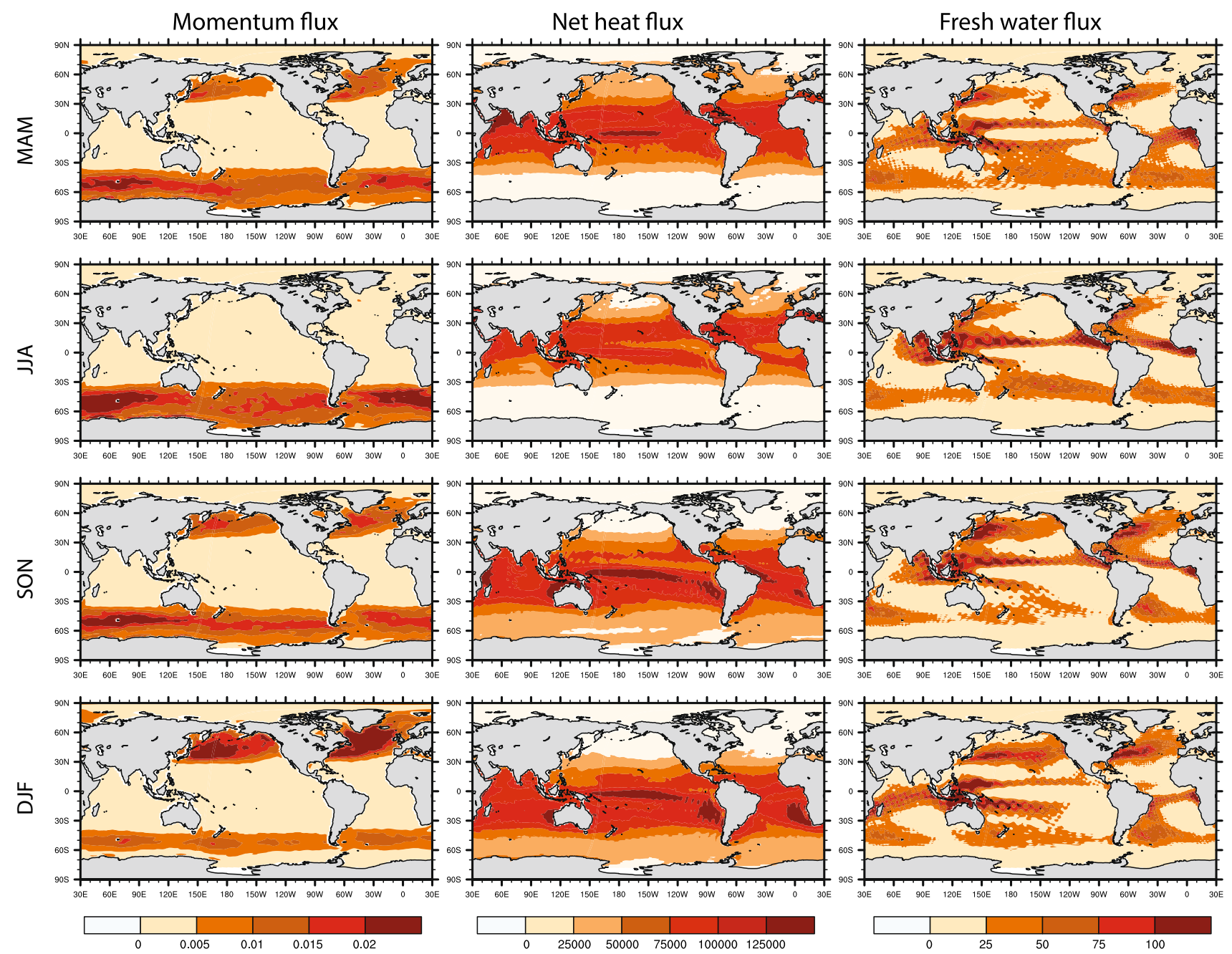

Fig. 5 The seasonal means of the variances of diurnal and intra-diurnal fluctuations for the magnitude of momentum flux (left column, $\mathrm{Pa}^{2}$ ), the net heat flux (middle column $\left(\mathrm{W} / \mathrm{m}^{-2}\right)^{2}$ ) and the fresh water flux (right column $\left(\mathrm{mm} /\right.$ day) ${ }^{2}$ ) in MAM, JJA, SON and DJF. Hourly fluxes in experiment $\mathrm{HC}$ are used

\subsection{Regarding the extremes}

Since the daily averaging alone cannot induce changes in the mean, the changes in the time-mean fluxes have to result from high-frequency feedbacks. We expect these feedbacks to be most intense during extreme events. Following Sect. 3.1, the total effect of hourly coupling on extreme values is examined by comparing the 90th and 10th percentile (hereafter $q_{90}$ and $q_{10}$ ) of hourly fluxes in experiments $H C$ with those of daily fluxes in experiment $D C\left(q_{10 h, H C} / q_{10_{d, D C}}, q_{90 h, H C} / q_{90_{d, D C}}\right)$. For the magnitude of momentum flux, $q_{10}$ and $q_{90}$ indicate the extremely weak and strong fluxes, respectively. For the net heat flux and fresh water flux, $q_{10}$ indicates the extreme large negative (upward) fluxes and $q_{90}$ indicates the extreme large positive (downward) fluxes. 


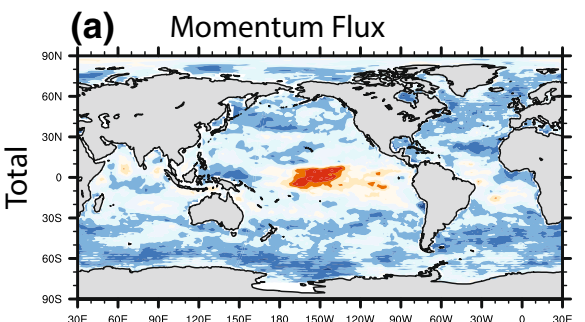

(d)

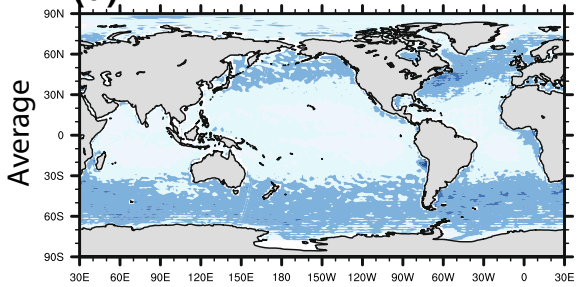

(g)

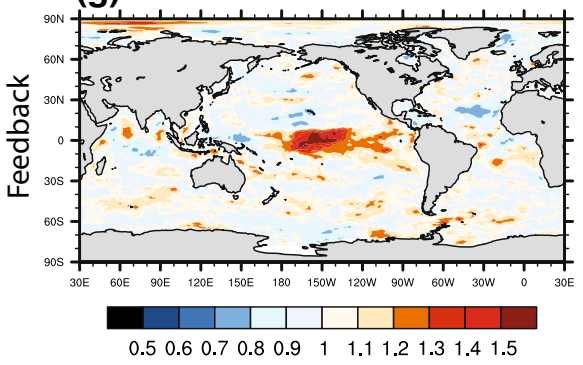

(b)

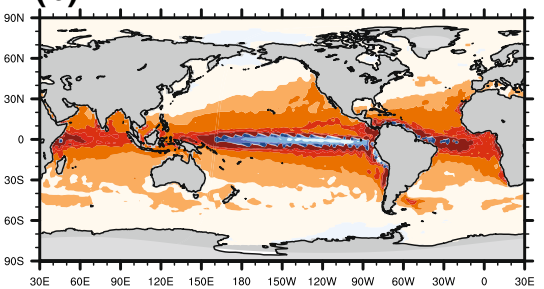

(e)

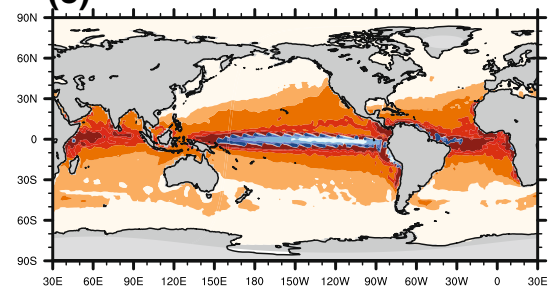

(h)

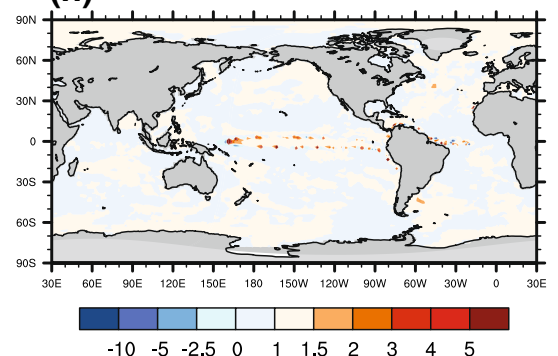

(c) Fresh Water Flux

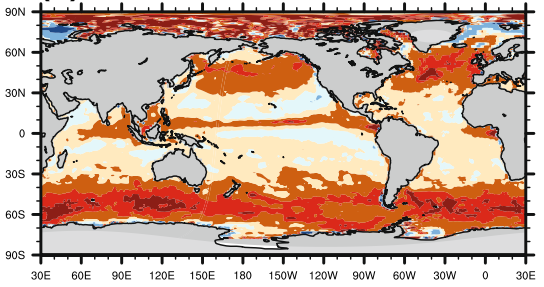

(f)

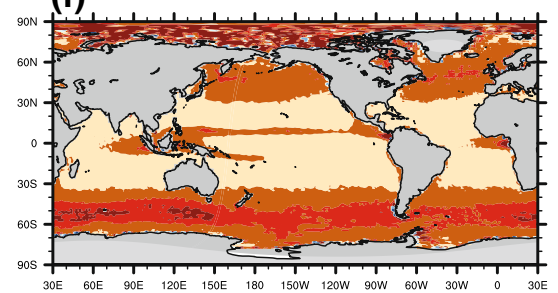

(i)

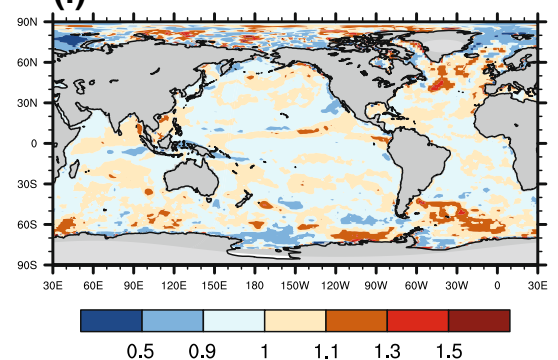

Fig. 6 Relative changes of the 10th percentiles with respect to the total changes in $\mathbf{a}-\mathbf{c}$, changes caused by averaging in $\mathbf{d}-\mathbf{f}$ and the changes caused by feedbacks in $\mathbf{g}-\mathbf{i}$. The changes are expressed as the ratio $q_{10}{ }_{H C} / q_{10} D C$

In most regions outside the tropics, extremely weak momentum fluxes $\left(q_{10}\right)$ become up to $30 \%$ weaker in experiment $H C$ than in experiment $D C$ (Fig. 6a), and the extremely strong momentum fluxes (90th percentiles) become about $15 \%$ stronger in the $H C$ than in $D C$ (Fig. 7a). These percentile changes suggest that increasing the coupling frequency makes the extremes become more frequent. In the tropics, the opposite is found. Increasing coupling frequency makes the extremes less frequent. The extremely weak momentum fluxes become less weak in the central equatorial Pacific, with the 10th percentiles being up to $30 \%$ larger in $H C$ than in $D C$ (Fig. 6a). The magnitudes of extremely strong momentum fluxes in the western tropical Pacific become less strong, with the magnitudes up to $15 \%$ smaller in $H C$ than those in $D C$ (Fig. 7a).

For the net heat flux (Figs. 6b, 7b), the diurnal cycle dominates the intra-diurnal fluctuations. Including the diurnal cycle increases the extreme downward (as characterized by $q_{90}$ ) and extreme upward (as characterized by $q_{10}$ ) net heat flux cases remarkably. The ratios for both $q_{90}$ and $q_{10}$ are larger than one almost everywhere, reaching a value of 5 for extreme downward flux in some tropical areas. In the equatorial Pacific, $q_{10}$ is negative (indicating upward flux) in experiment $H C$. However, In experiment $D C$, averaging out the diurnal cycle strongly reduces the probability of having upward fluxes so that $q_{10}$ is positive (indicating downward flux) (not shown). As a result, the ratio for $q_{10}$ is negative there (Fig. 6b).

The net fresh water flux results mainly from intermittent precipitation events and continuous evaporation. Increasing the coupling frequency leads to increases in $q_{10}$ in the Southern Ocean and in the North Pacific and North Atlantic as well as partly in the equatorial Pacific (Fig. 6c). This indicates increases in the extremes of negative (upward) fluxes related to strong evaporation there, with maximum increase reaching about $50 \%$. The increase in evaporation results likely from larger wind stress magnitudes in experiment $H C$ than in experiment $D C$. Increasing the coupling frequency increases also the $q_{90}$ in the storm track regions over the Southern Ocean, in the ITCZ and SPCZ, indicating stronger precipitation in these regions (Fig. 7c). The maximum increase in precipitation reaches about $40 \%$. In the North Pacific and North Atlantic, increasing the coupling frequency enhances mostly precipitation in the southern flanks of the storm tracks. In the central equatorial Pacific, where evaporation dominates precipitation in the model, the 90th percentile is negative (not shown), corresponding to weak precipitation there. Increasing the 


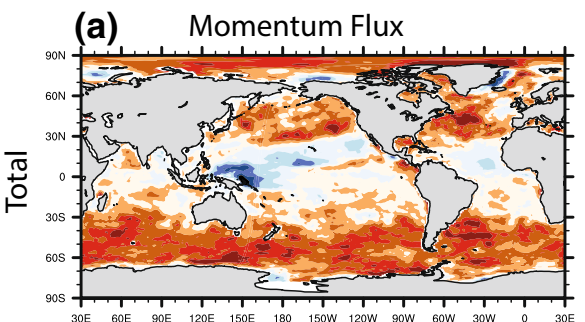

(d)

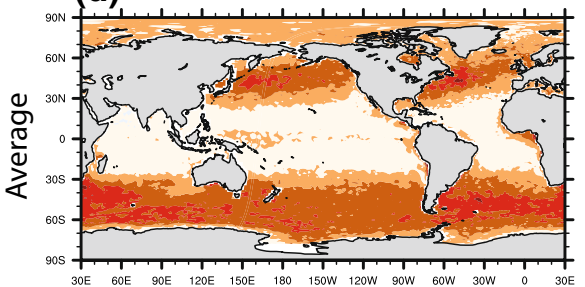

(g)

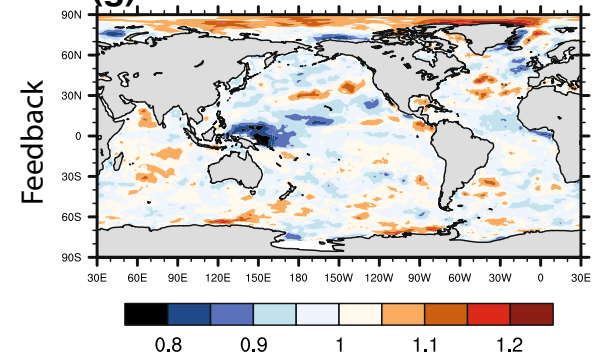

(b)

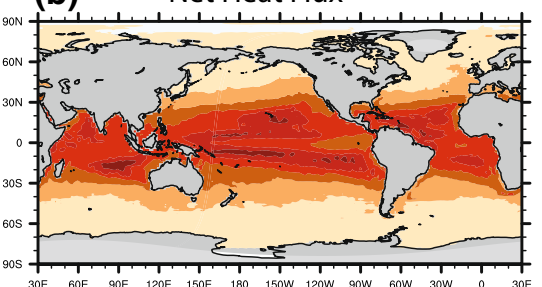

(e)

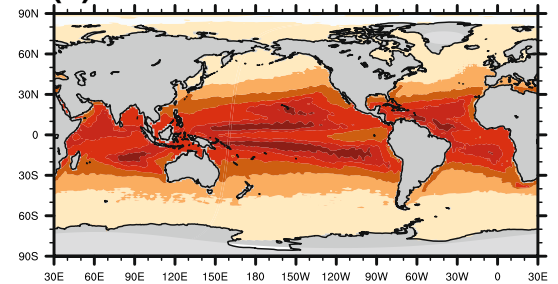

(h)

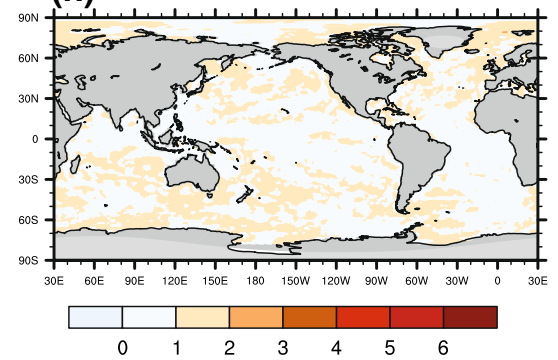

(c) Fresh Water Flux

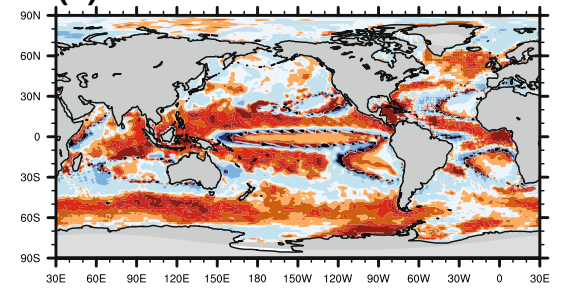

(f)

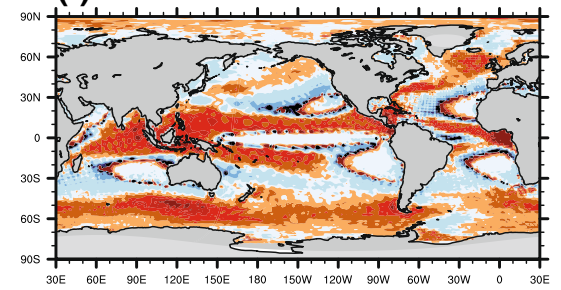

(i)

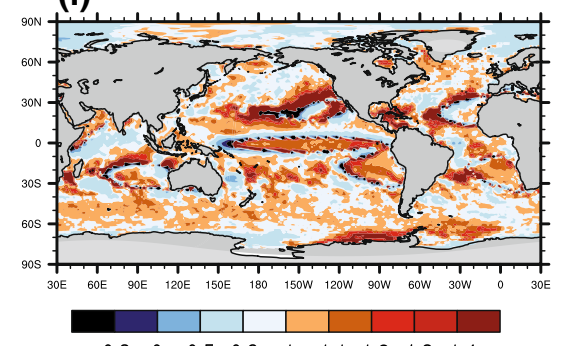

$\begin{array}{lllllllll}-0.3 & 0 & 0.5 & 0.9 & 1 & 1.1 & 1.2 & 1.3 & 1.4\end{array}$

Fig. 7 Relative changes of the 90th percentiles with respect to the total changes in $\mathbf{a}-\mathbf{c}$, changes caused by averaging in $\mathbf{d}-\mathbf{f}$ and the changes caused by feedbacks in $\mathbf{g}-\mathbf{i}$. The changes are expressed as the ratio $q_{90}{ }_{\mathrm{HC}} / q_{90} \mathrm{DC}$

coupling frequency increases evaporation, enhancing the ratio $q_{90, h, H C} / q_{90, d, D C}$ (Fig. 7c). A notable decrease in precipitation is found around $30^{\circ} \mathrm{S}$ and $30^{\circ} \mathrm{N}$, where precipitation is generally weak.

The effects from daily averaging and feedbacks are compared (Figs. 6d-f vs. g-i, $7 d-f$ vs. g-i). The total effect of increasing the coupling frequency results mainly from the daily averaging (Figs. $6 \mathrm{~d}-\mathrm{f}, 7 \mathrm{~d}-\mathrm{f}$ ) as their spatial structures and the magnitude are comparable to those related to the total changes (Figs. 6a-c, 7a-c). Exceptions are found for the wind stress magnitude in the tropics where high-frequency feedbacks act to reduce the extremes (Figs. 6g, 7g). High-frequency feedbacks have also an impact on extremes of daily precipitation events (Fig. 7i). In particular, the feedbacks reduce the area of the dry regions in the subtropical North Pacific and subtropical North Atlantic when increasing the coupling frequency. Near the northern boundaries of these dry regions, the 90th percentile, which is mostly negative, has larger magnitudes in experiment $H C$ than in $D C$. Consequently, $q_{90, d, H C} / q_{90, d, D C}$ are larger than one. In the central equatorial Pacific, where the 90th percentiles are negative, high-frequency feedbacks enhance evaporation. As shown in Figs. 6h and 7h, high-frequency feedbacks have little effect on the net heat flux, which is dominated by a strong diurnal cycle.

\subsection{A comparison with observation}

The above analysis shows that for the heat flux, daily averaging reduces variances by a factor of 15 and extremes (in form of $q_{10}$ and $q_{90}$ ) by a factor of 5. To confirm that the strong variations and the large extremes of the net heat flux in experiment $\mathrm{HC}$ exist in the real world, we consider the hourly net heat flux of TOGA COARE $3.0 \mathrm{~b}$ at 11 moorings available from the TAO project (Tropical Atmosphere Ocean project) (Fairall et al. 2003). For the comparison, hourly heat flux located at 11 grid points closed to the moorings are selected from experiments HC.

The comparison of the hourly time series of net heat flux in experiment $\mathrm{HC}$ and observation shows that the hourly coupled MPI-ESM simulates the diurnal cycle very well, with the maximum values close to $800 \mathrm{~W} / \mathrm{m}^{-2}$ in the noon and minimum around $-150 \mathrm{~W} / \mathrm{m}^{-2}$ in the night (not shown). Because of realistic simulating of the diurnal cycle of the net heat flux in experiment $\mathrm{HC}$, bias of the considered statistics are strongly decreased when increasing the coupling frequency from once per day to once per hour. 
To evaluate the bias of the considered statistics, we define the relative bias in experiment $\mathrm{HC}$ and $\mathrm{DC}$ as $\left(\left|S_{h, H C}-S_{h, O B S}\right| /\left|S_{h, O B S}\right|\right)$ and $\left(\left|S_{d, D C}-S_{h, O B S}\right| /\left|S_{h, O B S}\right|\right)$, respectively. $S_{h, H C}, S_{d, D C}$ and $S_{O B S}$ indicate the statistical quantities on each grid point in experiment $\mathrm{HC}$, DC and the observation. The mean of the relative biases at the considered 11 grid points are taken as the mean relative bias. In experiment $\mathrm{HC}$, the mean relative bias of the variance, skewness, $q_{10}$ and $q_{90}$ are very small, with values of $0.110,0.093,0.194$ and 0.069 , respectively. In experiment DC, however, the mean relative bias are substantially larger, with values up to $0.963,1.533,1.084$ and 0.764 , respectively.

\section{Large scale feedbacks related to changes in surface fluxes}

The analysis of the previous section focuses on changes in air-sea fluxes at each grid point. One important feature is the change in the mean magnitude of wind stress (shown in Fig. 1d), which is characterized by a decrease of wind stress magnitude over the Equatorial Pacific and a dipole pattern of wind stress over the Southern Ocean. These large scale changes may result from interactions between largescale feedback modes between SST and wind stresses, which will be analysed below.

\subsection{The methods}

To understand large scale feedbacks in the Southern Ocean and Equatorial Pacific, we consider anomalies of zonal mean SST and zonal mean zonal wind stress in the Southern Ocean $\left(20^{\circ} S-80^{\circ} S\right)$ and the fields of anomalies of SST and zonal wind stress in the Equatorial Pacific $\left(10^{\circ} S-10^{\circ} \mathrm{N}\right.$, $\left.120^{\circ} \mathrm{W}-90^{\circ} \mathrm{W}\right)$. The dominant SST-modes are identified as the leading EOF obtained by performing EOF analysis on SST anomalies of experiment HC. The anomalies are obtained by subtracting the monthly climatological values from the respective hourly time series.

To identify modes of wind stress, which emerge when dominant SST-modes are strong, we project SST anomalies in experiment $\mathrm{HC}$ and those in experiment $\mathrm{DC}$ onto the same dominant SST-mode obtained by performing EOF analysis on SST anomalies in experiment $\mathrm{HC}$ to produce the amplitude time series. Using the resulting time series, we then calculate the composites of wind stress anomalies in the respective experiments. The wind stress composites related to the positive phase of SST-modes are obtained when the time series of SST-modes are larger than one standard deviation; the wind stress composites related to the negative phase of the SST-modes are obtained when the time series of the SST-modes are smaller than minus

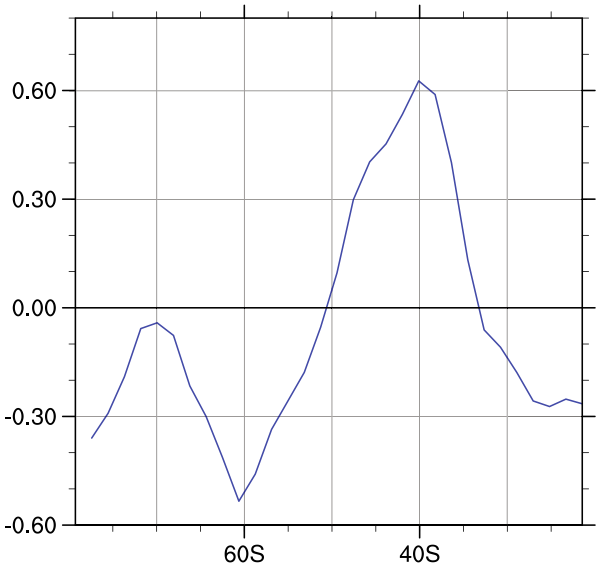

Fig. 8 EOF1 of zonal mean of SST anomalies (K) in latitudes of $20^{\circ} \mathrm{S}-80^{\circ} \mathrm{S}$

one standard deviation. The analysis is done for both the region in the Southern Ocean and the region in the Equatorial Pacific.

\subsection{Southern Ocean}

The dominant mode of SST in the Southern Ocean, as expressed in form of the first EOF of zonal mean SST in experiment HC (Fig. 8) shows a dipole with colder SST at the latitudes between $50^{\circ} \mathrm{S}-70^{\circ} \mathrm{S}$ and warmer SST between $50^{\circ} S-35^{\circ} S$. The composites of zonal wind stress related to the positive and negative phase of the SST mode are shown by black solid and dashed lines in Fig. 9a, respectively. The structure of the composites suggests that warmer SSTs are related to weaker wind stress and colder SSTs are related to stronger wind stress. The relation is consistent with the idea that stronger winds lead to larger sensible and latent heat fluxes and stronger mixing which tend to generate colder SST, a known feature characteristic for large-scale air-sea interactions. The SST mode in turn, in particular the SST anomalies over $50^{\circ} \mathrm{S}-60^{\circ} \mathrm{S}$ further strengthen the existing climatological mean temperature gradient there, leading to a further strengthening of wind stress at these latitudes. This interaction will be referred to as the SST-wind-stress feedback hereafter.

To quantify to what extent this feedback exists in experiment $D C$, composites of wind stress anomalies in experiment $D C$ that are related to the SST-mode in Fig. 8 are derived. The black solid line (dashed) in Fig. 9b show the positive (negative) phase of the composite. The general result that warmer SSTs are related to weaker wind stresses and colder SSTs are related to stronger wind stresses is also found in experiment $D C$.

The main difference between experiment $\mathrm{HC}$ and $\mathrm{DC}$ is the net effect described by the sum of the positive and 
(a) $\mathrm{HC}$

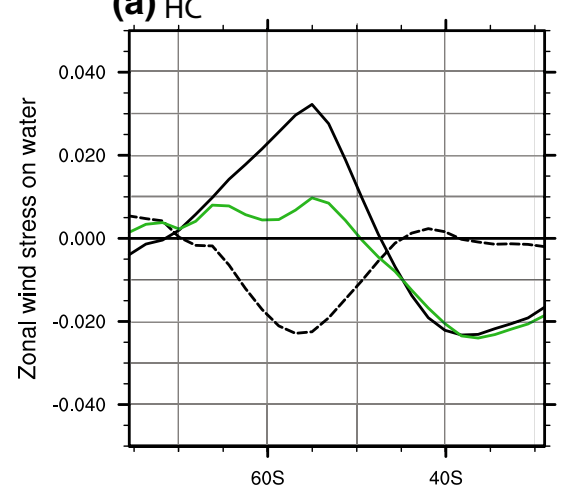

(b) $\mathrm{DC}$

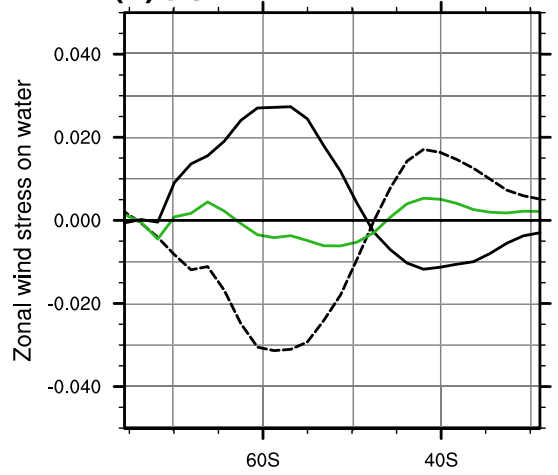

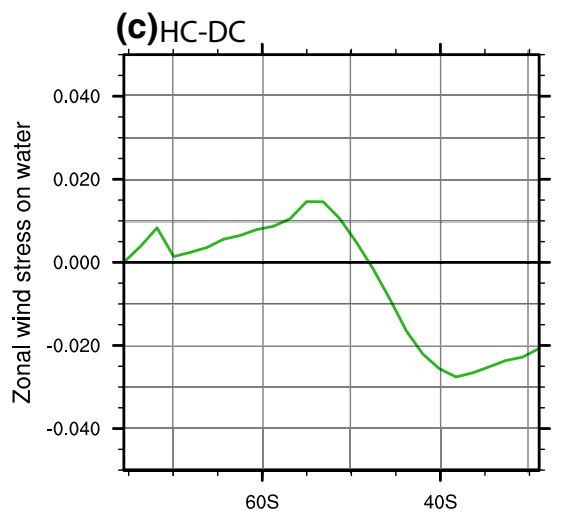

(d) $\mathrm{HC}$

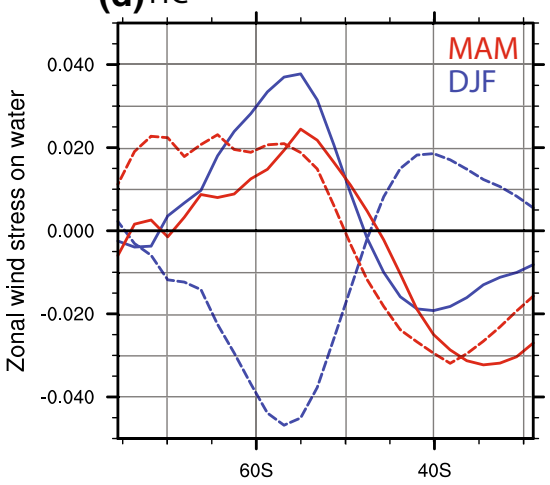

$$
\text { (e) } D C
$$

Fig. 9 Composites of zonal-mean zonal wind stress (Pa) a based on time series obtained by projecting hourly SST anomalies in experiment HC on EOF1 in Fig. 8, b based on time series obtained by projecting daily SST anomalies in experiment DC on EOF1 in Fig. 8. d based on time series obtained by projecting hourly SST anomalies in MAM (red) and DJF (blue) in experiment HC on EOF1 in Fig. 8. e

negative composites (green lines in Fig. 9a, b). The net effects in experiment $D C$ and $H C$ are, by and large, out of phase. The difference of the two green lines (Fig. 9c), which shows the effect of the coupling frequency on the wind stress related to the SST mode, suggests that it is the change of the wind stress associated with the SST mode that produce the dipole structure in Fig. 1d.

To understand why in the Southern Ocean the wind stress in relation to the SST mode behaves differently in experiment $D C$ than in $H C$, we decompose the composites of zonal wind stress into different seasons. We find that Fig. 9a, b result mainly from the composites in MAM and DJF. In SON and JJA, the wind stress anomalies related to the SST-mode are negligible (not shown). In experiment $H C$, the composites related to the positive and negative phase of the SST-mode are in-phase in MAM (red lines Fig. 9d). This in-phase relation leads to a re-enhancement of the net effect. In DJF, the composites related to the positive and negative phase of the SST-mode are out-of-phase, leading to a cancellation of the net effect. Because of the re-enhancement in MAM, the net wind stress related to the

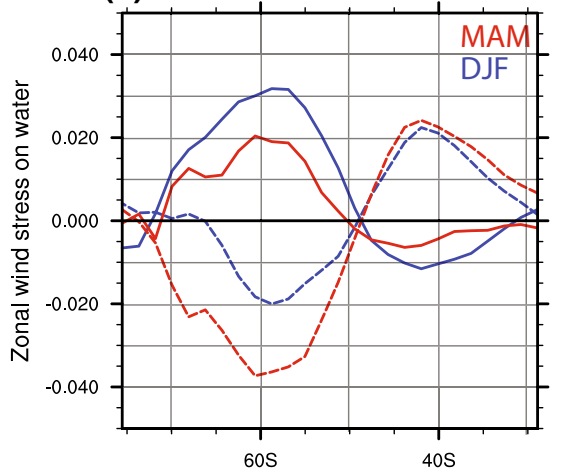

based on the time series obtained by projecting daily SST anomalies in MAM (red) and DJF (blue) in experiment DC on EOF1 in Fig. 8. Solid (dashed) lines are the composite related to the positive (negative) SSTa pattern in Fig. 8, green lines are the net effect. c shows the difference of the net effect in experiment $\mathrm{HC}$ and DC

SST mode, as characterized by the sum of the positive and negative composites, reveals a strengthening of wind stress at latitude $50^{\circ} S-70^{\circ} S$ and a weakening at latitude north of $50^{\circ} S$. In experiment $D C$, because the positive and negative composite patterns are out-of-phase in both DJF and MAM, the net wind stress related to the SST-mode does not favour a strengthening of wind stress south of $50^{\circ} \mathrm{S}$ and a weakening north of $50^{\circ} \mathrm{S}$.

The described difference between experiment $D C$ and $H C$ can be related to the seasonality in SST. The maximum magnitude of the dominant SST-mode (Fig. 8) is about $0.6^{\circ} \mathrm{C}$. In a cold season when high-latitude SSTs are close to the freezing point, the dominant SST-mode could be much less efficient in supporting any SST-wind-stress feedback. The SST in the Southern Ocean is colder in experiment $H C$ than in experiment $D C$. In the warmest seasons, namely the DJF in experiment $D C$ and $H C$ and the MAM in experiment $D C$, the wind stress related to the SST mode displays a dipole structure with stronger wind stress being associated with colder SST and weaker wind stress being associated with warmer SST. The relation is not found for 
(a)

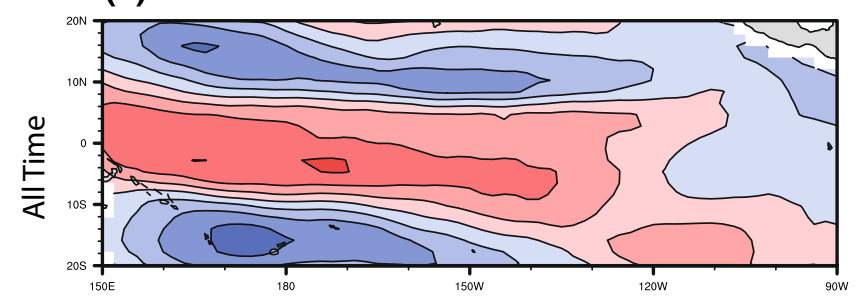

(c)

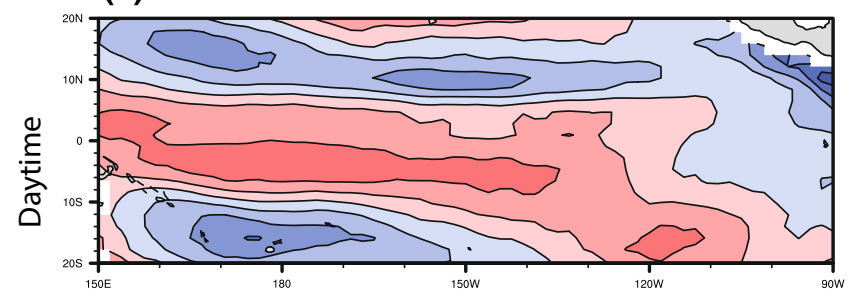

(e)

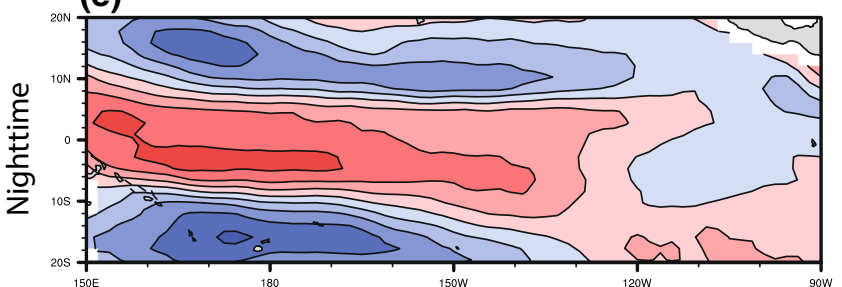

(b)

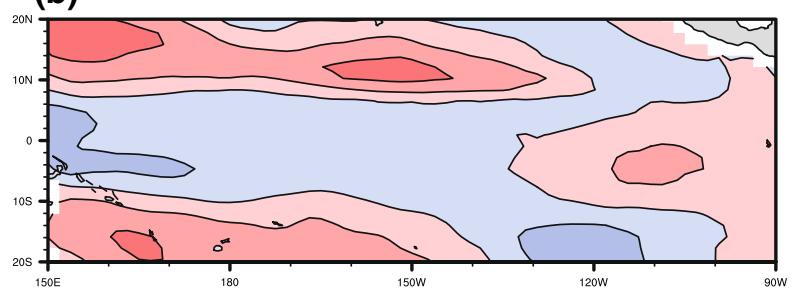

(d)

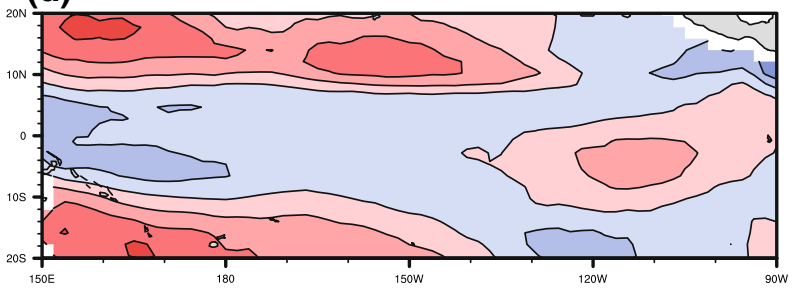

(f)

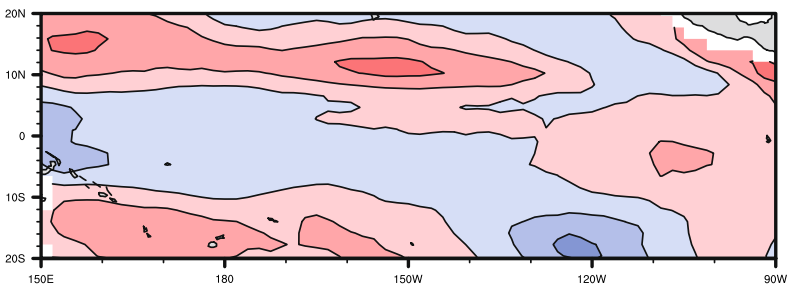

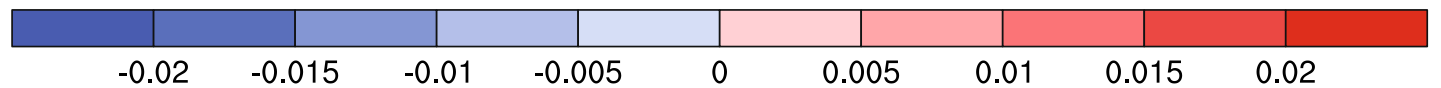

Fig. 10 Composites of zonal wind stress anomalies (Pa) in experiment HC for the El Niño phase (a) and La Niña phase (b). Both phases are further decomposed by composing wind stress anomalies at day $(\mathbf{c}, \mathbf{d})$ and night $(\mathbf{e}, \mathbf{f})$ time

colder seasons. In MAM in experiment $H C$, which is colder than MAM in experiment $D C$, the stronger wind stress is associated with warmer SST and weaker wind stress is associated with colder SST. In the coldest seasons, namely the SON and the JJA in both experiment $H C$ and $D C$, no significant wind stress anomalies related to the SST-mode are found. This dependence on the seasonality of SST can be responsible for the differences in the SST-wind-stress feedback between experiment $H C$ and $D C$ and, thus, for the increase in the wind stress in the Southern Ocean when the coupling frequency is increased (Figs. 9c, 1d).

\subsection{Equatorial Pacific}

The systematic decrease in wind stress magnitude along the Equatorial Pacific (Fig. 1d), which is mainly caused by the change of the zonal wind stress, might be related to ENSO. To understand such a feedback, we diagnose the dominant mode of tropical SSTs and quantify the large-scale structures in zonal wind stress that occur when the dominant SST-mode is strong in both experiments as outlined in Sect. 4.1. For this purpose, we perform EOF analysis on the SST anomaly in the tropical Pacific $\left(10^{\circ} \mathrm{S}-10^{\circ} \mathrm{N}, 120^{\circ} \mathrm{W}\right.$ $-90^{\circ} \mathrm{W}$ ) in experiment $H C$. The dominant SST-mode shows an ENSO event (not shown), characterized by the warmer SSTs in the central and eastern Pacific and the colder SSTs in the western tropical Pacific.

The wind stress anomaly related to the El Niño phase is described by the composite (Fig. 10a) obtained when the magnitude time series, i.e. PC1, is larger than one standard deviation, and that related to the La Niña phase is described by the composite (Fig. 10b) obtained when PC1 is smaller than minus one standard deviation. The composites suggest that a strong El Niño phase is connected to a stronger westerly anomaly along the equator. This is consistent with the Bjerknes feedback (Bjerknes, 1969) that warmer SST anomalies in the central and eastern Pacific that lead to a decreased zonal SST gradient result in weaker easterly wind stresses, which in turn further amplify the warming in the central and eastern Pacific.

Figure $10 \mathrm{a}-\mathrm{b}$ show that the zonal wind stress anomalies during the El Niño phase are much larger than those during 
Fig. 11 The sum of zonal wind stress $(\mathrm{Pa})$ composites related to the El Niño and La Niña phase for $\mathbf{a} \mathrm{HC}, \mathbf{b}$ DC. $\mathbf{c}$ shows the difference HC-DC (a) $\mathrm{HC}$

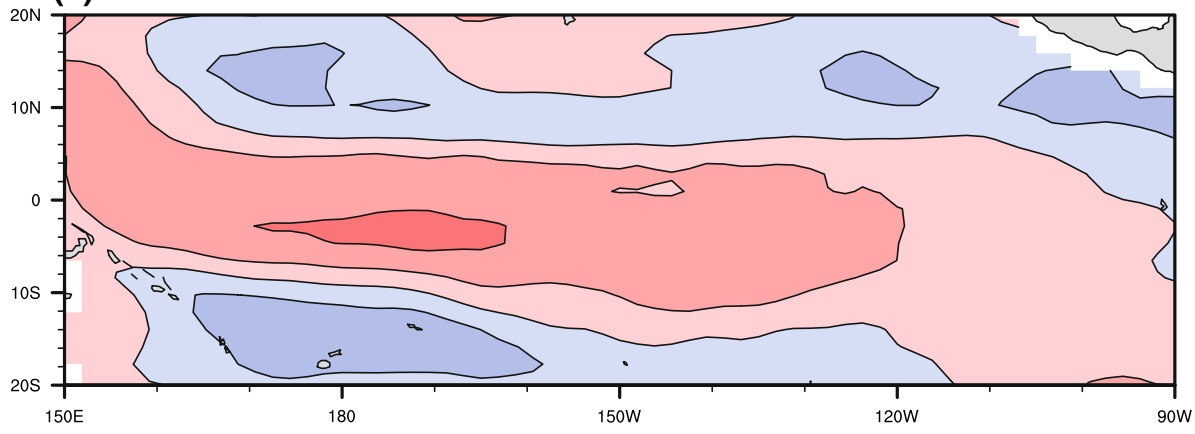

(b) DC

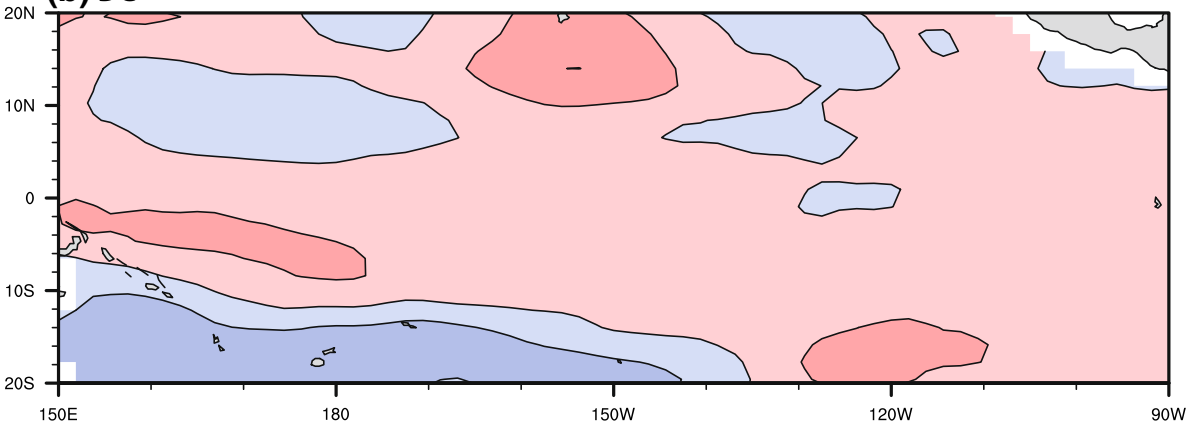

(c) HC - DC

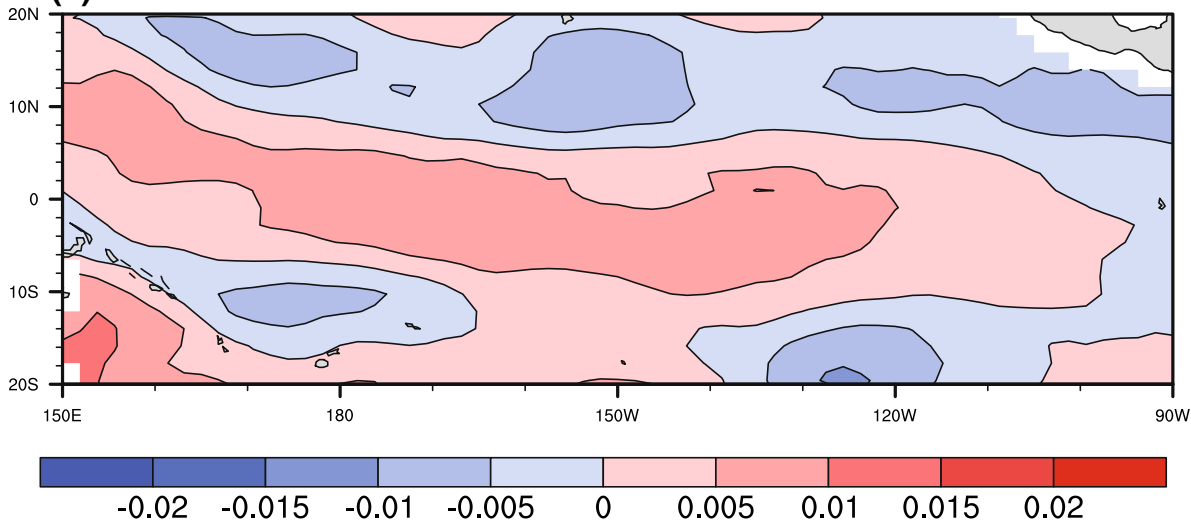

a La Niña phase. As a result, the net effect (El Niño phase + La Niña phase) would be a stronger westerly anomaly, i.e. a decrease in the easterly wind stress along the Equatorial Pacific (Fig. 11a). To understand why the wind stress does not have the same magnitude during El Niño and La Niña events in experiment $\mathrm{HC}$, we decompose the composites in Fig. 10a, b into daytime and nighttime. Daytime (nighttime) is defined as the time at which solar radiation is larger (smaller) than $50 \mathrm{~W} / \mathrm{m}^{2}$. We find that zonal wind stress anomalies appear to be stronger during nighttime (Fig. 10e) than during daytime (Fig. 10c) during an El Niño phase, but have comparable amplitudes at daytime and nighttime during a La Niña phase (Fig. 10d, f). Therefore, the Bjerknes feedback reveals a diurnal cycle during the El Niño events, with the feedback being stronger at the night than at the day time, and no clear diurnal cycle during the
La Niña events. This diurnal cycle of Bjerknes feedbacks during El Niño events leads to the net effect in experiment $H C$ shown in Fig. 11a.

In experiment $D C$, the diurnal cycle of the Bjerknes feedback can not be reproduced since fluxes are exchanged on a daily basis, so the composites during El Niño and La Niña have comparable magnitudes (not shown) making the net effect in experiment $D C$ weaker than that in experiment $H C$ (Fig. 11b). The difference of the net wind stress in the two experiments (Fig. 11c) shows stronger westerly anomalies of the zonal wind stress along the equator in experiment $\mathrm{HC}$ than in experiment $D C$. As the climate state of the zonal wind stress along the equator is easterly, the westerly anomaly of zonal wind stress indicates a decrease of the easterly wind stress. Hence, it is the diurnal cycle of the Bjerknes feedback during El Niño events that decreases 
the magnitude of wind stress in the Equatorial Pacific in Fig. 1d.

\section{Conclusions}

Using hourly coupling instead of daily coupling in MPIESM leads to changes in the statistics of air-sea fluxes. The changes can be separated into two different effects: one results from the daily averaging and the other from the high frequency feedbacks. With respect to the mean, significant changes are found for the magnitude of momentum flux, with an increase of up to $10 \%$ over the Southern Ocean and a decrease of up to $7 \%$ in the Equatorial Pacific. These changes have to be attributed to feedbacks.

Hourly coupling increases the variances by up to $50 \%$ for the magnitude of momentum flux, up to $100 \%$ for the fresh water flux and up to 15 times for the net heat flux. These increases are mainly due to the daily averaging which removes a considerable amount of the variance that is related to high-frequency turbulent fluctuations in the momentum flux and the fresh water flux in the mid- and high-latitude regions and to the diurnal cycle of the net heat flux. Exceptions are found in the tropics, where feedbacks reduce the variances, most significantly those of the momentum and fresh water flux. The diurnal and intra-diurnal variations resolved in $H C$ vary in their strengths with seasons and amount up to 50-90\% of the respective total variances.

Extremes are generally reduced by daily coupling, as the daily averaging smooths out the extremes. The reduction in the 10th and 90th percentiles reaches between 10 and $20 \%$ for momentum fluxes, about $40 \%$ for fresh water fluxes, and about a factor 5 for the net heat flux. Exceptions are found in the tropics, in particular over the Equatorial Pacific, where the weak momentum fluxes over the central Equatorial Pacific are strengthened, the strong momentum fluxes over the western Equatorial Pacific are weakened, and the weak evaporations over central Equatorial Pacific are enhanced. These extremes seem to be related to positive feedbacks between high-frequency extremes and SST.

By separating the total changes between $H C$ and $D C$ into those induced only by the daily averaging and those induced by feedbacks, we found that the daily averaging has a strong effect on variations and extremes, in particular for the net heat flux globally and for the momentum and fresh water fluxes in the mid and high-latitudes. High frequency feedbacks are important for the mean momentum fluxes both over the Equatorial Pacific and over the Southern Ocean and for the variances and extremes of momentum and fresh water fluxes in the tropical Pacific.

In the Southern Ocean, the SST-wind-stress feedback, characterized by weaker/stronger wind stress anomalies over warmer/colder SST and the re-enforcement of anomalies related to changes in temperature gradients, is different in experiments $H C$ and $D C$. The difference seems to arise from the background SST, with the SST-wind-stress feedback being only found when the background SST is sufficiently warm. Because SST is colder in experiment $H C$, the SST-wind-stress feedback is modified. This modification results in the increase of the magnitude of wind stress over the Southern Ocean.

In the Equatorial Pacific, the decrease of the magnitude of the wind stress is related to the diurnal cycle of Bjerknes feedback which cannot be simulated by the experiment DC. In experiment $H C$, the Bjerknes feedback has a diurnal cycle during the El Niño events with enhanced westerly anomalies at the nighttime but weaker ones at the daytime. In La Niña events, there is no clear diurnal cycle. This results in westerly anomalies on average along the equator in experiment HC. As the climate mean wind stress in the Equatorial Pacific is easterly, the magnitude of the wind stress is weaker in experiment $\mathrm{HC}$ than in experiment DC.

Besides the influence on the magnitude of wind stress in the Equatorial Pacific, the diurnal cycle of Bjerknes feedback in the Equatorial Pacific might also be related to the simulation of ENSO in experiment $H C$, and the change of the mean SST in the tropical Pacific. To understand why the Bjerknes feedback exhibits a diurnal cycle and how this diurnal cycle affects the mean SST requires additional work.

Acknowledgments Fangxing Tian was financially supported by Chinese Academy of Science (CAS), Max Planck Institute for Meteorology (MPI-M), Max Planck Society (MPG) and International Max Planck Research School on Earth System Modelling (IMPRS-ESM). We acknowledge the TAO Project Office of NOAA/PMEL. Thanks to Irina Fast for her assistance in setting up the model experiments. Thanks to Stephan Bakan and Jochem Marotzke for reviewing the manuscript. Open access funding provided by Max Planck Society (or associated institution if applicable).

Open Access This article is distributed under the terms of the Creative Commons Attribution 4.0 International License (http://creativecommons.org/licenses/by/4.0/), which permits unrestricted use, distribution, and reproduction in any medium, provided you give appropriate credit to the original author(s) and the source, provide a link to the Creative Commons license, and indicate if changes were made.

\section{Appendix}

\section{Oceanic boundary layer processes in MPIOM}

In MPIOM, the first model layer is $12 \mathrm{~m}, 8$ layers are within the upper $90 \mathrm{~m}$, and 20 layers are within the upper $600 \mathrm{~m}$. The mixed layer processes in the model are parametrized based on a modified Pacanowski and Philander scheme (PP scheme, Pacanowski and Philander (1981)). Vertical mixing and diffusion are based on the Richardson-number dependent 
formulation. In addition, wind mixing in the upper ocean is assumed to be proportional to the cube of the $10 \mathrm{~m}$ wind speed, decaying exponentially with depth (Marsland et al. 2003). The penetration of the sunlight is parametrized by an exponential decay of the downward short wave heat flux with depth, whereby taking the water colour defined by Jerlov (1976) into account. In the CMIP5 version of MPIOM, which is also the version considered in this paper, a globally uniform water colour, corresponding to IA Jerlov water type, is used.

Although the oceanic boundary processes are parametrized in a quite crude way, without explicitly parametrized smallscale processes like cool skin and Langmuir circulation, the basic features of SST and mixed-layer depth are well reproduced by MPI-ESM (Jungclaus et al. 2013). By comparing with the SST from PHC3 climatology (Levitus et al. 1998; Jungclaus et al. 2013) showed that the model SST biases are in the range of the state-of-art coupled models. By comparing with mixed-layer depth derived from observations (Kara et al. 2003; Carton and Giese 2008; Jungclaus et al. 2013) showed that the climatological mean mixed-layer depth is well simulated in MPI-ESM, except for some convectively active regions in the Southern Ocean near the Antarctic coasts.

The realism of SST and mixed-layer depth on diurnal and intra-diurnal timescales is difficult to assess due to lack of globally covered high-frequency observations. Nevertheless, a comparison of model SST simulated at a grid point close to the location of $140^{\circ} \mathrm{W}, 0^{\circ} \mathrm{N}$ shows that the model can realistically simulate the diurnal cycle of SST at that point (Fig. 12). For the mixed-layer depth, no high-frequency observation is available. A consideration at a few grid point in the central tropical Pacific suggests that the simulated diurnal variation is

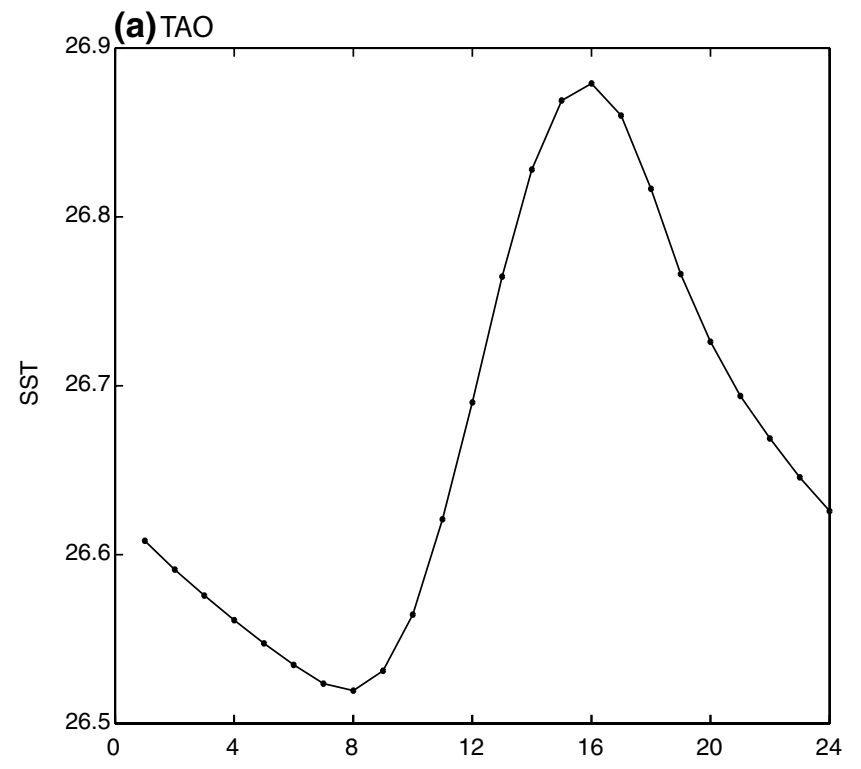

physically meaningful. The result at one grid point is shown in (Fig. 13): At the nighttime, the surface ocean loses heat and becomes unstable, the mixed-layer depth increases. At the daytime, when the solar radiation warms the ocean surface, it becomes stable and the mixed-layer depth decreases. We hence expect that MPI-ESM can simulate the main features of diurnal variations of SST and mixed-layer depth.

\section{Atmospheric boundary layer processes in ECHAM6}

The vertical structure of ECHAM6 is discretized following the method of Simmons and Burridge (1981) and employs a hybrid sigma-pressure coordinate system on a Lorenz grid. Given the surface pressure as $1013.25 \mathrm{hPa}$, there are about 5 levels in the boundary layers (below around $1000 \mathrm{~m}$ or $900 \mathrm{hPa}$ ).

The planetary boundary layer model in ECHAM6 is developed by Roeckner et al. (1992). The boundary layer parametrization is based on the eddy diffusivity/viscosity approach, where the eddy viscosity consists of the product of a velocity scale and a length scale. The velocity scale is based on the square root of the turbulent kinetic energy, which is described by a prognostic equation following Brinkop and Roeckner (1995).

In ECHAM6, cumulus convective clouds and stratiform clouds are treated differently. The shallow and mid-level (elevated moist layer) convection scheme are the Tiedtke formulation(Tiedtke 1989), deep (including congestus) convection scheme is the Nordeng formulation (Nordeng 1994).

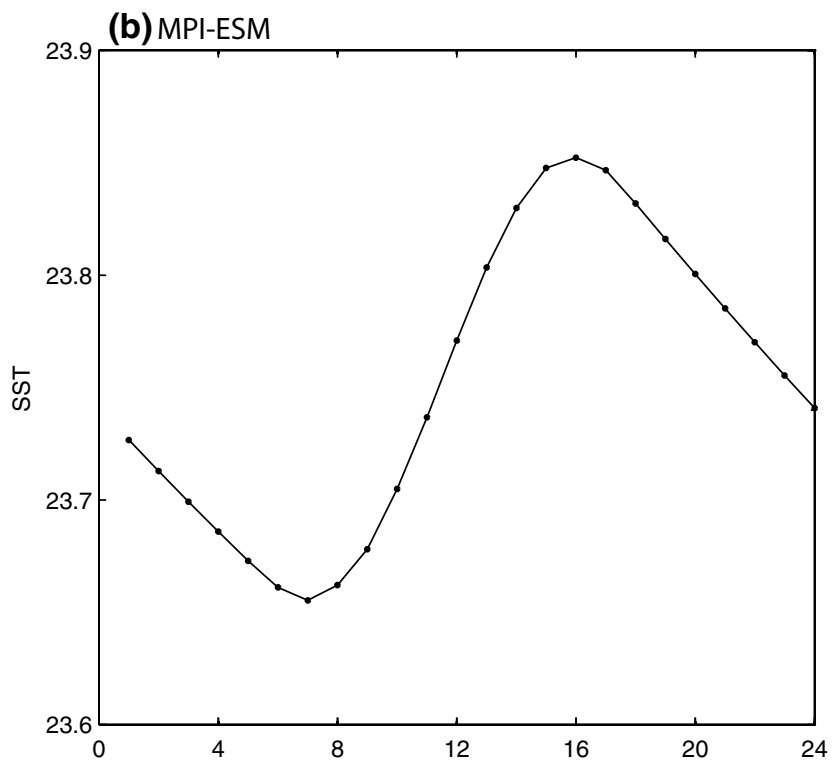

Fig. 12 a Diurnal cycle of SST obtained from a mooring near $\left(0^{\circ} \mathrm{N}, 140^{\circ} \mathrm{W}\right)$. b Diurnal cycle of SST at grid point near $\left(0^{\circ} \mathrm{N}, 140^{\circ} \mathrm{W}\right)$ by hourly coupled MPI-ESM 
Fig. 13 A 5-day hourly time series of mixed-layer depth at grid point near $\left(0^{\circ} \mathrm{N}, 140^{\circ} \mathrm{W}\right)$ by hourly coupled MPI-ESM

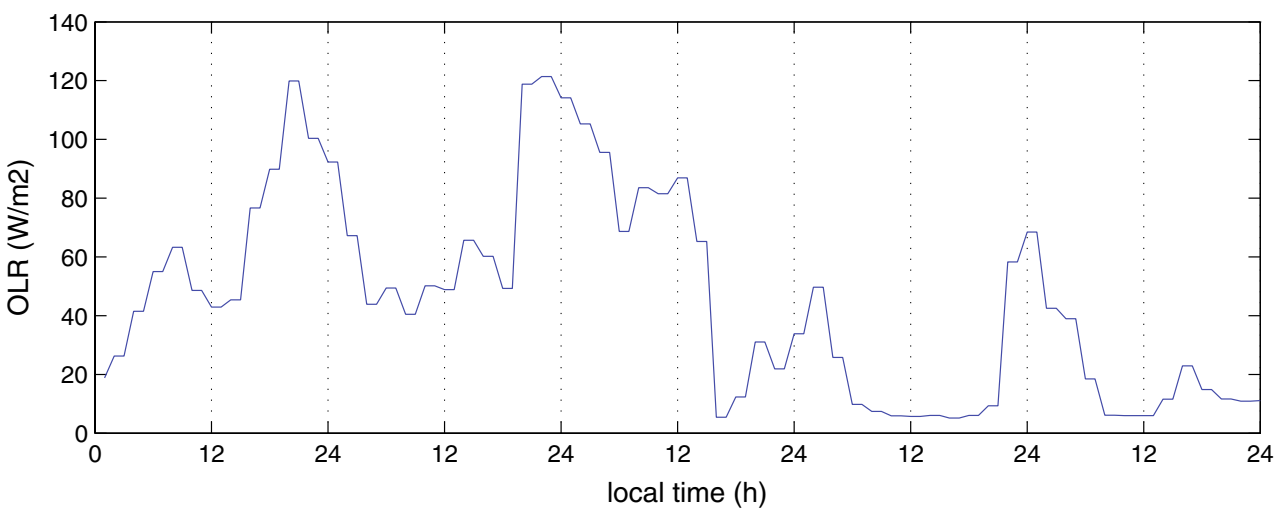

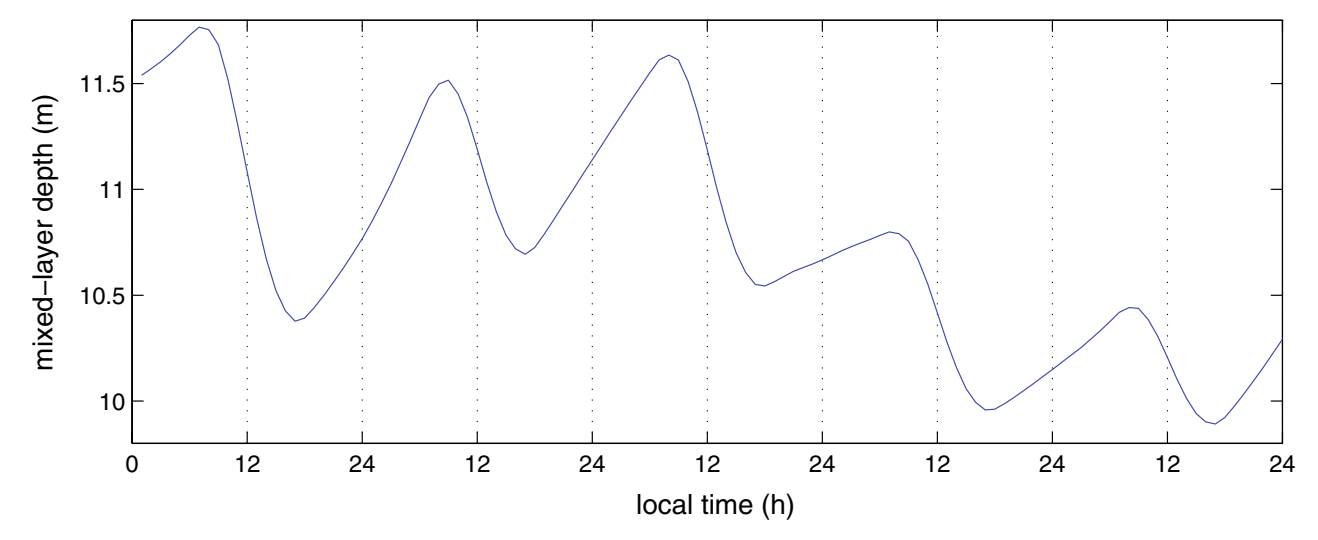

Fig. 14 A 5-day hourly time series of OLR (full sky-clear sky) at grid point near $\left(10^{\circ} \mathrm{N}, 180^{\circ} \mathrm{E}\right)$ by hourly coupled MPI-ESM
The scheme for the representation of stratiform clouds consists of prognostic equations for the vapour, liquid and ice phase, respectively, a cloud microphysical scheme (Lohmann and Roeckner 1996), and a diagnostic cloud cover scheme (Sundqvist et al. 1989). By comparing with observations from GPCP (Adler et al. 2003), Stevens et al. (2013) suggested that ECHAM performs similar to other climate models and shows similar biases, but the amplitude of the biases in ECHAM6 is slightly smaller than in ECHAM5.

The diurnal cycle of the precipitation in ECHAM6 has been studied by Hohenegger and Stevens (2013). By comparing with 3-hourly observations from TRMM data (Huffman et al. 2007), they found that ECHAM6 produces the diurnal cycle of precipitation realistically, with more precipitation in the nighttime and less in the daytime over the ocean, though it peaks too early in the nighttime. For the diurnal cycle of the convection, analysis of Outgoing Longwave Radiation (OLR) at a few grid points in the tropical Pacific along $10^{\circ} \mathrm{N}$ and $10^{\circ} \mathrm{S}$ indicates that the diurnal cycle of convection is physically meaningful. The result of one grid point (Fig. 14) shows that: at the daytime convection over the ocean is weaker than that at the nighttime.

\section{Parametrizations of air-sea fluxes}

Here we summarize the parametrizations of air-sea fluxes, i.e. the exchanges of momentum, heat and fresh water between atmosphere and the ocean, that are directly affected by coupling frequency.

\section{Wind stress}

The wind stress $\boldsymbol{\tau}$ is calculated from the velocity difference between the near surface wind speed and the ocean surface currents (Pacanowski 1987):

$\boldsymbol{\tau}=\rho C_{D}|\mathbf{W}-\mathbf{V}|(\mathbf{W}-\mathbf{V})$

where $\rho$ is the density of air and $C_{D}$ is the drag coefficient. $\mathbf{W}$ is the wind vector at the lowest atmosphere level and $\mathbf{V}$ is the ocean velocity vector of the surface level.

\section{Net heat flux}

The net heat flux $Q_{s r f}$ is defined as the sum of sensible and latent heat flux and shortwave and longwave radiation : 
$Q_{s r f}=Q_{s r f}^{s e}+Q_{s r f}^{l a}+Q_{s r f}^{l w}+Q_{s r f}^{s w}$

where $Q_{s r f}^{s e}, Q_{s r f}^{l a}, Q_{s r f}^{l w}$ and $Q_{s r f}^{s w}$ indicate the sensible, latent, long-wave and short-wave heat fluxes, respectively.

The sensitive and latent heat flux are parameterized as (Oberhuber 1993):

$Q_{s r f}^{s e}=\rho_{a} c_{a} C_{H} V_{10 m}\left(T_{a}-T_{s r f}\right)$

$Q_{s r f}^{l a}=\rho_{a} L_{s r f} C_{L} V_{10 m}\left(q_{a}-q_{s r f}\right)$

$\rho_{a}$ and $c_{a}$ are constants denoting the air density and the specific capacity for air, $L_{s r f}$ denotes the latent heat of vaporization or sublimation. Variable coefficients of sensible heat flux $C_{H}$ and latent heat flux $C_{L}$ are formulated according to Large and Pond (1982). $V_{10 m}$ indicates the $10 \mathrm{~m}$ wind speed. $T_{a}$ and $q_{a}$ are the air temperature and specific humidity at the $2 \mathrm{~m}$ level. $T_{s r f}$ is the ocean model upper layer temperature or the ice/snow layer skin temperature. $q_{s r f}$ is specific humidity at the surface.

The long-wave and short-wave radiations are parameterized as:

$$
\begin{aligned}
Q_{s r f}^{l w}= & \epsilon \sigma T_{a}^{4}\left(0.39-0.05 \sqrt{e / 100}\left(1-\chi n^{2}\right)\right. \\
& +4 \epsilon \sigma T_{a}^{3}\left(T_{s r f}-T_{a}\right) \\
Q_{s r f}^{s w}= & \left(1-\alpha_{s r f}\right) Q^{i n c s w}
\end{aligned}
$$

where $n, \epsilon$ and $\sigma$ are the fractional cloud cover, surface thermal emissivity and Stephan-Boltzmann constant, respectively. $e$ is the saturation vapor pressure calculated based on the formulae of Buck (1981). $\chi$ is the cloudiness factor. $Q^{i n c s w}$ is the incident short-wave radiation which is the function of the solar zenith angle and is provided as part of the forcing data. $\alpha_{s r f}$ is the surface reflectivity (albedo), which depends on surface properties.

\section{Fresh water flux}

The fresh water flux at the sea level $Q_{\zeta}$ is defined as:

$Q_{\zeta}=P-E+R+G$

where $P, E, R$ and $G$ are fluxes of fresh water due to precipitation, evaporation, river run off and glacial melt water, respectively.

With these parametrizations, MPI-ESM produces realistic climatological mean air-sea fluxes. Hagemann et al. (2013) compared the long-term mean fluxes simulated by the MPI-ESM with those derived from recent satellite data sets and with those simulated by the CMIP3 version of MPI-ESM. It is found that the air-sea fluxes, especially the solar radiation, in the CMIP5 version of MPI-ESM are generally improved compared with that in the CMIP3 version, which was already one of the best preforming CMIP3 models (Reichler and Kim 2008).

\section{References}

Adler RF et al (2003) The version-2 global precipitation climatology project (gpcp) monthly precipitation analysis (1979-present). J Hydrometeorol 4(6):1147-1167

Bernie D, Guilyardi E, Madec G, Slingo J, Woolnough S (2007) Impact of resolving the diurnal cycle in an ocean-atmosphere $\mathrm{gcm}$. part 1: a diurnally forced $\mathrm{ogcm}$. Clim Dyn 29(6):575-590

Bernie D, Guilyardi E, Madec G, Slingo J, Woolnough S, Cole J (2008) Impact of resolving the diurnal cycle in an ocean-atmosphere GCM. Part 2: a diurnally coupled CGCM. Clim Dyn 31(7-8):909-925

Bjerknes J (1969) Atmospheric teleconnections from the equatorial pacific 1. Mon Weather Rev 97(3):163-172

Brinkop S, Roeckner E (1995) Sensitivity of a general circulation model to parameterizations of cloud-turbulence interactions in the atmospheric boundary layer. Tellus A 47(2):197-220

Buck AL (1981) New equations for computing vapor pressure and enhancement factor. J Appl Meteorol 20(12):1527-1532

Carton JA, Giese BS (2008) A reanalysis of ocean climate using simple ocean data assimilation (SODA). Mon Weather Rev 136(8):2999-3017

Danabasoglu G, Large WG, Tribbia JJ, Gent PR, Briegleb BP, McWilliams JC (2006) Diurnal coupling in the tropical oceans of CCSM3. J Clim 19(11):2347-2365

Fairall C, Bradley EF, Hare J, Grachev A, Edson J (2003) Bulk parameterization of air-sea fluxes: updates and verification for the coare algorithm. J Clim 16(4):571-591

Giorgetta MA, Roeckner E, Mauritsen T, Bader J, Crueger T, Esch M, Rast S, Kornblueh L, Schmidt H, Kinne S, Hohenegger C (2013) The atmospheric general circulation model ECHAM6-model description. Max-Planck-Institut für Meterologie, Deutshland

Guemas V, Salas-Mélia D, Kageyama M, Giordani H, Voldoire A (2013) Impact of the ocean diurnal cycle on the North Atlantic mean sea surface temperatures in a regionally coupled model. Dyn Atmos Oceans 60:28-45

Hagemann S, Loew A, Andersson A (2013) Combined evaluation of MPI-ESM land surface water and energy fluxes. J Adv Model Earth Syst 5(2):259-286

Ham S, Hong S-Y, Park S (2014) A study on air-sea interaction on the simulated seasonal climate in an ocean-atmosphere coupled model. Clim Dyn 42(5-6):1175-1187

Hertwig E, von Storch J-S, Handorf D, Dethloff K, Fast I, Krismer T (2015) Effect of horizontal resolution on ECHAM6-AMIP performance. Clim Dyn 45(1-2):185-211

Hohenegger C, Stevens B (2013) Controls on and impacts of the diurnal cycle of deep convective precipitation. J Adv Model Earth Syst 5(4):801-815

Huffman GJ et al (2007) The TRMM multisatellite precipitation analysis (TMPA): quasi-global, multiyear, combined-sensor precipitation estimates at fine scales. J Hydrometeorol 8(1):38-55

Jerlov NG (1976) Marine optics, vol 14. Elsevier, Amsterdam, pp 175-192

Jungclaus $\mathrm{J}$ et al (2006) Ocean circulation and tropical variability in the coupled model ECHAM5/MPI-OM. J Clim 19(16):3952-3972

Jungclaus J et al (2010) Climate and carbon-cycle variability over the last millennium. Clim Past Discuss 6(3):1009-1044

Jungclaus $\mathbf{J}$ et al (2013) Characteristics of the ocean simulations in the Max Planck Institute Ocean Model (MPIOM) the ocean 
component of the MPI-earth system model. J Adv Model Earth Syst 5(2):422-446

Kara AB, Rochford PA, Hurlburt HE (2003) Mixed layer depth variability over the global ocean. J Geophys Res Oceans 108(C3):3079

Kuhlbrodt T, Monahan AH (2003) Stochastic stability of open-ocean deep convection. J Phys Oceanogr 33(12):2764-2780

Large W, Pond S (1982) Sensible and latent heat flux measurements over the ocean. J Phys Oceanogr 12(5):464-482

Levitus S, Boyer T, Conkright M, Johnson D, Antonov TJ, Stephens C, Gelfeld R (1998) World ocean database 1998, volume 2: Temporal distribution of mechanical bathythermograph profiles. NOAA Atlas NESDIS, 19

Lohmann U, Roeckner E (1996) Design and performance of a new cloud microphysics scheme developed for the ECHAM general circulation model. Clim Dyn 12(8):557-572

Marsland SJ, Haak H, Jungclaus JH, Latif M, Röske F (2003) The Max-Planck-Institute Global Ocean/Sea Ice model with orthogonal curvilinear coordinates. Ocean Model 5(2):91-127

Misra V, Marx L, Brunke M, Zeng X (2008) The equatorial pacific cold tongue bias in a coupled climate model. J Clim 21(22):5852-5869

Nordeng TE (1994) Extended versions of the convective parametrization scheme at ECMWF and their impact on the mean and transient activity of the model in the tropics. Reading. Tech. rep. Research Dept technical memorandum 206

Oberhuber JM (1993) Simulation of the atlantic circulation with a coupled sea ice-mixed layer-isopycnal general circulation model. Part I: model description. J Phys Oceanogr 23(5):808-829

Pacanowski R (1987) Effect of equatorial currents on surface stress. J Phys Oceanogr 17(6):833-838

Pacanowski R, Philander S (1981) Parameterization of vertical mixing in numerical models of tropical oceans. J Phys Oceanogr 11(11): 1443-1451

Reichler T, Kim J (2008) How well do coupled models simulate today's climate? Bull Am Meteorol Soc 89(3):303-311
Roeckner E et al (1992) Simulation of the present-day climate with the ECHAM model: impact of model physics and resolution. Max-Planck-Institut für Meteorologie, Hamburg

Seo H, Subramanian AC, Miller AJ, Cavanaugh NR (2014) Coupled impacts of the diurnal cycle of sea surface temperature on the Madden-Julian oscillation. J Clim 27(22):8422-8443

Simmons AJ, Burridge DM (1981) An energy and angular-momentum conserving vertical finite-difference scheme and hybrid vertical coordinates. Mon Weather Rev 109(4):758-766

Stevens B et al (2013) Atmospheric component of the MPI-M earth system model: ECHAM6. J Adv Model Earth Syst 5(2):146-172

Sundqvist H, Berge E, Kristjánsson JE (1989) Condensation and cloud parameterization studies with a mesoscale numerical weather prediction model. Mon Weather Rev 117(8):1641-1657

Terray P, Kamala K, Masson S, Madec G, Sahai A, Luo J-J, Yamagata $T$ (2012) The role of the intra-daily SST variability in the indian monsoon variability and monsoon-ENSO-IOD relationships in a global coupled model. Clim Dyn 39(3-4):729-754

Tiedtke M (1989) A comprehensive mass flux scheme for cumulus parameterization in large-scale models. Mon Weather Rev 117(8):1779-1800

Tziperman E (1986) On the role of interior mixing and air-sea fluxes in determining the stratification and circulation of the oceans. $J$ Phys Oceanogr 16(4):680-693

Valcke S, Caubel A, Declat D, Terray L (2003) OASIS ocean atmosphere sea ice soil user's guide. Technical report, Cent. Eur. Formation Avancee Calcul Sci., Toulouse, France

von Beena BS, von Storch J-S (2009) Effects of fluctuating daily surface fluxes on the time-mean oceanic circulation. Clim Dyn 33(1):1-18

Walin G (1982) On the relation between sea-surface heat flow and thermal circulation in the ocean. Tellus 34(2):187-195

Williams PD (2012) Climatic impacts of stochastic fluctuations in air-sea fluxes. Geophys Res Lett 39(10):1-6 